University of Wollongong

Research Online

Australian Institute for Innovative Materials -

Papers

Australian Institute for Innovative Materials

$1-1-2016$

\title{
Mineral-biochar composites: molecular structure and porosity
}

\author{
Aditya Rawal \\ University of New South Wales \\ Stephen D. Joseph \\ University of New South Wales, sjoseph@uow.edu.au \\ James M. Hook \\ University of New South Wales \\ Chee Chia \\ University of New South Wales \\ Paul R. Munroe \\ University of New South Wales
}

See next page for additional authors

Follow this and additional works at: https://ro.uow.edu.au/aiimpapers

Part of the Engineering Commons, and the Physical Sciences and Mathematics Commons

Research Online is the open access institutional repository for the University of Wollongong. For further information contact the UOW Library: research-pubs@uow.edu.au 


\title{
Mineral-biochar composites: molecular structure and porosity
}

\begin{abstract}
Dramatic changes in molecular structure, degradation pathway, and porosity of biochar are observed at pyrolysis temperatures ranging from 250 to $550^{\circ} \mathrm{C}$ when bamboo biomass is pretreated by iron-sulfateclay slurries (iron-clay biochar), as compared to untreated bamboo biochar. Electron microscopy analysis of the biochar reveals the infusion of mineral species into the pores of the biochar and the formation of mineral nanostructures. Quantitative 13C nuclear magnetic resonance (NMR) spectroscopy shows that the presence of the iron clay prevents degradation of the cellulosic fraction at pyrolysis temperatures of $250^{\circ} \mathrm{C}$, whereas at higher temperatures $\left(350-550^{\circ} \mathrm{C}\right)$, the clay promotes biomass degradation, resulting in an increase in both the concentrations of condensed aromatic, acidic, and phenolic carbon species. The porosity of the biochar, as measured by NMR cryoporosimetry, is altered by the iron-clay pretreatment. In the presence of the clay, at lower pyrolysis temperatures, the biochar develops a higher pore volume, while at higher temperature, the presence of clay causes a reduction in the biochar pore volume. The most dramatic reduction in pore volume is observed in the kaolinite-infiltrated biochar at $550{ }^{\circ} \mathrm{C}$, which is attributed to the blocking of the mesopores $(2-50 \mathrm{~nm}$ pore) by the nonporous metakaolinite formed from kaolinite.
\end{abstract}

\section{Disciplines}

Engineering | Physical Sciences and Mathematics

\section{Publication Details}

Rawal, A., Joseph, S. D., Hook, J. M., Chia, C., Munroe, P. R., Donne, S., Lin, Y., Phelan, D., Mitchell, D. R. G., Pace, B., Horvat, J. \& Webber, J. W. (2016). Mineral-Biochar Composites: Molecular Structure and Porosity. Environmental Science and Technology, 50 (14), 7706-7714.

\section{Authors}

Aditya Rawal, Stephen D. Joseph, James M. Hook, Chee Chia, Paul R. Munroe, Scott Donne, Yun Lin, David Phelan, David R. G Mitchell, Ben Pace, Josip Horvat, and J. Beau W. Webber 


\title{
Mineral Impregnated Biochars: Molecular Structure and Porosity
}

Aditya Rawal ${ }^{a^{*}}$, Stephen D. Joseph ${ }^{b^{*}}$, James M. Hook, ${ }^{a}$ Chee Chia ${ }^{b}$, Paul R. Munroe ${ }^{b}$, Scott Donne ${ }^{\mathrm{c}}$, Yun Lin ${ }^{\mathrm{c}}$, David Phelan ${ }^{\mathrm{h}}$, David R. G. Mitchell ${ }^{\mathrm{d}}$, Ben Pace ${ }^{\mathrm{b}}$, Joseph Horvat ${ }^{\mathrm{d}}$, J. Beau W. Webber ${ }^{\mathrm{e}, \mathrm{f}}$.

${ }^{a}$ Mark Wainwright Analytical Centre, University of New South Wales, Kensington, NSW, Australia 2052

b School of Materials Science and Engineering, University of New South Wales, Kensington, NSW, Australia 2052

${ }^{c}$ University of Newcastle, School of Environmental and Life Sciences, Office C325, Chemistry, Callaghan, New South Wales 2308, Australia

${ }^{d}$ Electron Microscopy Centre, AIIM, University of Wollongong, Wollongong NSW, 2522, Australia

${ }^{\mathrm{e}}$ Lab-Tools Ltd., Canterbury Enterprise Hub, University of Kent, Canterbury, Kent. CT2 7NJ.

${ }^{\mathrm{f}}$ Institute of Petroleum Engineering, Heriot-Watt University, Edinburgh. EH14 4AS.

${ }^{\mathrm{h}}$ University of Newcastle, Electron Microscope and X-Ray Unit, Callaghan, New South Wales 2308, Australia

* Corresponding authors. Tel.: +6129385 4693; fax: +6129385 4663 .

E-mail address: a.rawal@unsw.edu.au; s.joseph@unsw.edu.au

Aditya Rawal and Stephen Joseph had equal intellectual and experimental inputs into this paper and are the principal leads in the work.

\begin{abstract}
Biochar synthesized by pyrolysis $\left(250{ }^{\circ} \mathrm{C}-550{ }^{\circ} \mathrm{C}\right)$ of bamboo, which is treated by infiltration with kaolinite/bentonite-iron sulfate slurries, yields structures that are significantly different compared to the untreated-bamboo biochar. Transmission electron microscopy (TEM) analysis reveals the infusion of mineral species into the pores of the biochar and formation of mineral nano-structures. Quantitative ${ }^{13} \mathrm{C}$ Nuclear Magnetic Resonance (NMR) shows that the presence of clay prevents degradation of the cellulosic
\end{abstract}


fraction at pyrolysis temperatures of $250{ }^{\circ} \mathrm{C}$. However, at pyrolysis temperatures of $350{ }^{\circ} \mathrm{C}$ and above, the clay promotes the biomass degradation, resulting in an increase in the degree of aromatic condensation and the concentrations of acidic and phenolic species. The porosity of the biochar, as measured by NMR cryo-porosimetry, is altered by the presence of the clay mineral. In particular, the presence of the clay increases the pore volume of the biochar at a pyrolysis temperature of $250{ }^{\circ} \mathrm{C}$, while at $550{ }^{\circ} \mathrm{C}$, the clay reduces the pore volume.

Keywords: biochar, clays, solid state NMR, TEM, cryoporometry.

\section{INTRODUCTION}

Agricultural residues are one of the main sources of sustainable biomass in the world today ${ }^{1}$. However, in China and other parts of South East Asia, an estimated 100 million tonnes of biomass are burnt annually, either in the field or at processing factories. This results in loss of carbon and nutrients from the soil and a very large increase in harmful atmospheric carbon emissions ${ }^{2}$. Biochar production is seen as a key part of a strategy to effectively recycle biomass carbon and nutrients ${ }^{3}$, improve plant growth and mycorrhizal colonization $^{4}$, improve soils physical and chemical properties, provide a source of renewable energy and act as a means for carbon sequestration ${ }^{1,5-7}$. These vast quantities of readily available biomass, which are currently treated as waste for disposal, could be readily, cost effectively and widely converted into valuable biochar ${ }^{1,8-10}$. For biochar production to be cost effective, its properties need to be tailored for specific applications, as has been the case for activated carbons for engineering applications ${ }^{2,11-12}$. The addition of clay, minerals and organic matter to biomass before pyrolysis and/or after pyrolysis can result in increased crop yields and improvement of soil biome at application rates similar to those used for chemical fertilizers $3-4,11,13-16$. Furthermore, we propose to implement strategies similar to those used for activated carbons to design biochar with superior properties tailored to specific applications ${ }^{2,11-12}$.

Agricultural residues collected from fields are often coated in a small, but significant quantity of soil that typically contains a range of clays, organic matter, sand, salts, residual chemical fertilizers (e.g. urea) and minerals that include nano-phase ironbearing compounds ${ }^{17}$. Joseph et. al, ${ }^{11}$ and Li et. al ${ }^{18}$ have suggested that the favorable plant 
response to these biochars could be due to a number of factors including: the enhanced redox activity from the interaction between these minerals and the pyrolyzed biomass, the ensuing biotic and abiotic reactions assisting in nutrient cycling and plant uptake of nutrients ${ }^{11,18}$.

Despite the significant advantages of such enriched biochar, there has been very little research on how such surface coatings on the biomass changes the yields and properties of the biochar. Standards for biochar stability and properties currently being developed by the International Biochar Initiative ${ }^{19}$ are primarily based on clean feedstock in stand-alone pyrolysis facilities. Biochar produced from feedstock that have been standing in fields for considerable periods of time or synthesized in simple ovens and kilns may have very different properties. For example, previous work has demonstrated that biomass pyrolyzed with kaolin or montmorillonite at $600{ }^{\circ} \mathrm{C}$ resulted in a biochar that had a greater surface exchange capacity and adsorption capacity for contaminants than the biochar produced without such amendements ${ }^{20}$. Elsewhere, it was found that addition of biochar (along with bamboo vinegar) to composting piles enhances nitrogen conservation and immobilized heavy metal ions ${ }^{21}$.

While the structure of biochar as a function of pyrolysis conditions has been investigated $^{22-23}$, to the best of our knowledge there has been no systematic study on the changes in the molecular and structural properties of biochar produced from biomass coated with mineral phases. Furthermore, although mineral- biochar composites are a subject continuing research interest, much of the work has been focused on their properties or applications $20,24-25$ and within the literature there is generally only a qualitative understanding the molecular structure of the mineral impregnated biochar ${ }^{14,26}$. This study attempts to bridge this gap in knowledge and is the first in a series that examines the interaction of biomass, clay and minerals species with respect to the molecular structure and the micro- and meso-porosity of the biochar. The aim of this study is to understand the effect of co-pyrolysing biomass with clay and $\mathrm{FeSO}_{4}$ on the degree of carbon condensation, the concentration of functional groups in the biochar, the porosity of the biochar and the pyrolysis degradation pathway. The degree of carbon condensation is directly relevant to the stability of the biochar and its environmental implications relating to carbon sequestration. ${ }^{27-28}$ The concentrations of different functional groups, such as carboxylic 
acids, and the porosity of the biochar are pertinent to the agricultural applications of biochar, while the ability to control the degradation pathway will be crucial for efficient production of the desired engineered biochar structure.

\section{MATERIALS AND METHODS}

Synthesis of biochars. A set of standard biochars was designed to minimize mineral and chemical variation of a naturally sourced lignocellulose feedstock, by cutting segments from a single 1 meter section of bamboo for all experiments performed. The bamboo section was cut into cubes with a dimension of approximately $10 \mathrm{~mm}$. Refined kaolinite and bentonite clays were sourced from source for clay minerals: Keens Ceramics, Gindurra Rd., Sommersby, NSW, 2250, while $\mathrm{FeSO}_{4} .7 \mathrm{H}_{2} \mathrm{O}$ was sourced from Sigma Aldrich. Two different clay mineral slurries were prepared to infiltrate the biomass with the minerals. The first was iron-kaolinite slurry comprising a 1:1 by weight ratio of $\mathrm{FeSO}_{4} .7 \mathrm{H}_{2} \mathrm{O}$ and refined kaolinite clay. The second slurry was iron-bentonite slurry prepared from a $1: 1$ by weight ratio of $\mathrm{FeSO}_{4} \cdot 7 \mathrm{H}_{2} \mathrm{O}$ and bentonite clay. Two sets of samples were prepared by soaking the bamboo cubes in the two clay mineral slurries at 80 ${ }^{\circ} \mathrm{C}$ for 3 hours. The slurry temperature was optimized to yield maximum infiltration of the slurry into the biomass pores without drying out the slurry over a 3 hour period. A third set of bamboo cubes was left untreated to act as a control. Thus, three sets of biomass samples were prepared and pyrolysed to form biochar at pyrolysis temperatures of $250{ }^{\circ} \mathrm{C}, 350{ }^{\circ} \mathrm{C}$, $450{ }^{\circ} \mathrm{C}$ and $550{ }^{\circ} \mathrm{C}$, making twelve samples in all. In the ensuing discussion, we label the biochar from untreated bamboo as $\mathrm{BC}$, biochar from bamboo treated with Kaolinite:FeSO slurry as BKF and biochar from bamboo treated with bentonite:FeSO 4 slurry as BBF. The detailed specifications of the bentonite and kaolinite clays are given in the supplementary information. Prior to pyrolysis the biomass samples were dried at $110{ }^{\circ} \mathrm{C}$ for 24 hours. Pyrolysis was carried out by heating the samples in an air starved environment at 3 ${ }^{\circ} \mathrm{C} /$ minute until the final pyrolysis temperature was attained. The samples were then held at this temperature for 30 minutes. The sample holders were quenched in water and then the biochar removed for further characterization. Three different batches from each of the biochar samples were produced and these were then crushed and combined for analysis. The sample codes and preparation conditions are summarized in Table 1. Analysis of the 
aggregated sample for ultimate and ash analysis was carried out 4 times (Table 1) as per ASTM D7582 29 . The ash constituent analysis was carried out using ASTM D4326 ${ }^{30}$ using $\mathrm{X}$-ray fluorescence (XRF) spectroscopy.

SEM and TEM. Scanning electron microscope (SEM) analysis was performed using a Zeiss Sigma SEM fitted with a Bruker X-ray energy dispersive spectrometry (EDS) detector on pieces of biochar that had been mounted on carbon tape and chromium coated. For transmission electron microscopy (TEM), the biochar samples were dispersed ultrasonically in ethanoland a drop of the suspension was placed on a carbon-coated copper grid with a pipette. The fine particles were examined using a JEOL 2100 TEM fitted with an Oxford EDS system.

Solid state NMR. The samples of biochar were finely ground and packed into 4 $\mathrm{mm}$ zirconia rotors with Kel-F caps. The ${ }^{13} \mathrm{C}$ NMR experiments were carried out on Bruker AVANCE III 300 spectrometer with a 7 Tesla superconducting magnet operating at frequencies of $300 \mathrm{MHz}$ and $75 \mathrm{MHz}$ for the ${ }^{1} \mathrm{H}$ and ${ }^{13} \mathrm{C}$ nuclei respectively. The ratios of the protonated and non-protonated carbon in the chars were determined according to the method of Brewer et $\mathrm{al}^{22}$. The quantitative ${ }^{13} \mathrm{C}$ direct polarization magic angle spinning $\left({ }^{13} \mathrm{C}\right.$ DPMAS) NMR spectra of the material were acquired at $12 \mathrm{kHz}$ MAS with a ${ }^{13} \mathrm{C}-90^{\circ}$ pulse length of $4 \mu \mathrm{s}, 80 \mathrm{kHz}{ }^{1} \mathrm{H}$ SPINAL64 decoupling, and a Hahn-echo before signal detection to eliminate baseline distortion. $10 \mathrm{~s}$ recycle delays were used for the measurements, where greater than $95 \%$ of the ${ }^{13} \mathrm{C}$ relaxation was observed as determined by ${ }^{13} \mathrm{C}$ cross-polarization/ $\mathrm{T}_{1}\left(\mathrm{CP} / \mathrm{T}_{1}\right)$ filter ${ }^{31}$. Selective suppression of the protonated carbon species was achieved with dipolar dephasing (dephasing time: $68 \mu \mathrm{s}$ ) before acquisition, and yielded a quantitative signal of the condensed and non-protonated carbon species. The typical measurement time for each ${ }^{13} \mathrm{C}$ DPMAS experiment was 11 hours. Details for the mineral analysis ${ }^{27} \mathrm{Al}$ and ${ }^{29} \mathrm{Si}$ solid state NMR are provided in the Supplementary material.

NMR Cryoporometry. The pore-size distribution and pore volumes of the stable carbon skeleton were assessed using a Lab-Tools Mk1 (1970s) solid-state NMR spectrometer with digital-switching transmitter. The magnet used was a low-field $(0.5 \mathrm{~T})$ Mullard permanent magnet with a $34 \mathrm{~mm}$ pole-gap, with a low homogeneity, often 
deliberately degraded to $100 \mu \mathrm{T}$ over the $12 \mathrm{~mm}$ long and $2.4 \mathrm{~mm}$ diameter sample, in order to have a clear echo at $1 \mathrm{~ms}$. The details of the method are given by Webber et al. ${ }^{32}$. Repeats were carried out on two additional samples and indicated a variation of \pm 0.15 $\mathrm{ml} / \mathrm{gm}$

\section{RESULTS}

Infiltration of the mineral phase into the biochar scaffold. The pyrolysis of the mineral slurry treated bamboo biomass results in the incorporation of the mineral phases into the biochar scaffold. The SEM images of the higher temperature mineral biochar composites, (BKF 450, BKF 550, BBF 450 and BBF 550), which are most relevant for potential applications, are shown in Figure 1 and illustrate the presence of the mineral in the biochars after they have reacted with the clay/Fe mixtures during pyrolysis. Figure 1(a) shows the coating of clay and iron that covers the outside of all of the biochars at low magnification as evidenced by the rough particulate material, while Figure 1(b) shows the macroporous structure of the biochar. SEM images of the lower temperature mineral biochar composites are provided in supplementary information (Figures S1 and S2). It is possible the surface roughening seen in Figure 1(a), may be from the texture of the biomass itself, therefore images were recorded at higher magnification, Figure 1(c) and (d), clearly show the mineral phases in the form of particles and agglomerates coating the surface of the biochar structure.. The SEM was not sufficiently resolved to see the morphology of the infiltrated mineral phases, therefore TEM analysis was used to investigate the mineral structure on the internal pore surface of the biochar. Figure 1(e), demonstrates that the internal surface of a biochar pore is indeed coated by mineral phases (present as darker particles). The larger pore is probably derived from the carbonization of phloem or xylem and contains a range of amorphous and crystalline nano-phases composed of ferric and alumino-silicate species. Away from this macro pore, we expect that minerals have probably impregnated existing mesopores. At higher magnification analysis, Figure 1(f) reveals that the mineral regions have a nano-structured dendritic morphology. The elemental analysis by energy dispersive spectroscopy (EDS) as shown in, Figure 1(g), indicates these dendritic nanostructures include an iron-bearing mineral phase. Thus, the SEM and TEM analyses indicate that soaking biomass with mineral slurry followed by 
pyrolysis can result in the incorporation of nanostructured mineral phases within the porous structure of the biochar. It is important to note that the SEM and TEM analysis provide a local picture of the mineral coating to biochar. As we show below, NMR spectroscopic analysis is required to establish mineral infiltration within the bulk of the biochar and its influence on the molecular structure and porosity of the biochar.

Elemental composition of the biochar. Table 1 summarizes the changes in the chemical composition of the biochar produced at different temperatures. With increasing pyrolysis temperature, the carbon content increases and the biochar yield decreases for the untreated $\mathrm{BC}$ series of biochar. This is expected as the oxygen-bearing and hydrocarbon moieties are volatilized at higher temperature. In the slurry-treated biomass (the BBF and BKF series), the volatilization process also results in increased concentration of the clay minerals (and a relative reduction of carbon content). It is important to note that the $\mathrm{Al}, \mathrm{Fe}$ and $\mathrm{S}$ content for the BKF and BBF samples was orders of magnitude greater than the BC samples (Table 1), indicating uptake of the minerals by the biomass. Similar uptake of iron sulfate and both clay minerals by the bamboo biomass from the slurry solution was also indicated by equivalent content of both $\mathrm{Fe}$ and $\mathrm{Al}$ for the $\mathrm{BBF}$ and $\mathrm{BKF}$ samples. The total $\mathrm{N}$ content was observed to be lower for the BBF450 and BBF550 samples compared with samples in the $\mathrm{BC}$ and $\mathrm{BKF}$ series. It is possible that the presence of the bentonite-iron minerals in the biochar promotes volatilization of the nitrogenous species from the biomass and further investigations need to be undertaken to pinpoint the origin of this specific effect. As the pyrolysis temperature increased, the concentrations of most of the mineral species increased due to concomitant reduction in the biomass fraction due to loss of the oxygen and hydrogen moieties during degradation and volatilization. The sulfur content for the $\mathrm{BBF}$ and $\mathrm{BKF}$ samples is reduced at $550{ }^{\circ} \mathrm{C}$ (after an initial increase at $250{ }^{\circ} \mathrm{C}$ due to reduction of the organic content) indicating a volatilization of sulfur which is consistent with the degradation of iron sulfate at $550{ }^{\circ} \mathrm{C}^{33}$. We finally note that the variation in the carbon wt. \% for the different biochars is not monotonic and is indicative of the differing molecular structures as well as the ash contents of the biochars. Thus to directly assess the differences in carbon matrix of the biochar, a quantitative ${ }^{13} \mathrm{C}$ Solid state NMR spectroscopy approach is taken. 
Molecular structure of the biochar. The combination of the TEM and the elemental analysis confirm the uptake and dispersion of mineral phases by the biomass from the slurries. The molecular structure analysis of the biochar was carried out by quantitative solid-state ${ }^{13} \mathrm{C}$ DPMAS NMR, which are shown in Figure 2. Distinct differences in the structure of the biochar as a function of the presence of clay and the pyrolysis temperatures are observed. At the lower pyrolysis temperature of $250{ }^{\circ} \mathrm{C}$ (Figure $2 \mathrm{a}-\mathrm{c}$ ), the influence of the clays is most significant and the presence of the clay retards the degradation of the cellulosic component. The ${ }^{13} \mathrm{C}$ NMR of the biochar contains signal from cellulose (105 ppm, 90 ppm, 75 ppm and 65 ppm), hemicellulose (which has additional peaks at 20.5 and $172 \mathrm{ppm})$ and lignin (165ppm - $110 \mathrm{ppm}$ and $55 \mathrm{ppm})$. A comparison of the intensity of the peak at $75 \mathrm{ppm}$ (representative of the cellulose) and the $-\mathrm{OCH}_{3}$ peak at $55 \mathrm{ppm}$ (representing the lignin) shows that the BKF250 and BBF250 chars have a significantly higher fraction of cellulose present, compared to the BC250 char. Concomitantly, there is a strong signal of alkyl species between 6-50 ppm for the BC250 char that corresponds to volatile degradation products (such as high molecular weight alkenes) from the cellulosic degradation. Although there is only about $1 \mathrm{wt} \%$ of clay in the BKF and BBF series of biochar, as per the ultimate analysis, the clay exerts a strong effect in suppressing the degradation of the cellulose. The degradation of biomass is dependent on heat transfer into the biomass particle, which is driven by conductive, convective and to a lesser extent by radiative mechanisms. For large particles, such as the bamboo sections used in the current work, and the relatively lower temperature $\left(250^{\circ} \mathrm{C}\right)$, convective heat transfer is expected to be an important heat transfer mechanism, particularly since the biomass is a poor conductor of heat. We hypothesize that the coating of clay on the biomass reduces the gas permeability of the ligno-cellulosic biomass thereby suppressing the convective heat transfer into the biomass and suppressing degradation. It is particularly well known for the case of clay-polymer nanocomposites ${ }^{34}$, where the incorporation of clay nanoparticles into the polymer matrix suppresses gas diffusion through the polymer due to its very large surface area $\left(\sim 1000 \mathrm{~m}^{2} / \mathrm{g}\right)$.

In contrast to the suppression of degradation at $250{ }^{\circ} \mathrm{C}$, at elevated pyrolysis temperatures $\left(350{ }^{\circ} \mathrm{C}\right.$ to $\left.550{ }^{\circ} \mathrm{C}\right)$, the mineral species appear to have an opposite effect. At 
$350{ }^{\circ} \mathrm{C}$ (Figure $2 \mathrm{~d}$-f) the structure of the untreated bamboo biochar (BC350) shows a strong signal for aromatic carbon species (160 ppm to $100 \mathrm{ppm}$ ) as well as aliphatic carbon species (50 ppm to $6 \mathrm{ppm}$ ). However, while the BKF350 and BBF350 biochar also show a strong aromatic signal, the signal intensity of the aliphatic species is reduced compared with that from the $\mathrm{BC} 350$ biochar. This difference is interpreted as an indicator that at the higher temperatures, the presence of clays promotes the formation of condensed carbon structure and enhances the cross-linking of the volatile aliphatic fraction into condensed aromatic species. This hypothesis is consistent with the documented ability of clay minerals to catalyze condensation and polymerization reactions from a variety of substrates. ${ }^{35-37}$ This effect is of particular importance, since the low-molecular weight degradation products have been shown to have a mutagenic potential ${ }^{38}$.At pyrolysis temperatures of $450{ }^{\circ} \mathrm{C}-550{ }^{\circ} \mathrm{C}$, the ${ }^{13} \mathrm{C}$ NMR signal is very similar in all the materials being centered at $\sim 130 \mathrm{pm}$ as see in Figure $2(\mathrm{~g}-\mathrm{l})$. The primary species produced at these temperatures have an aromatic carbon structure, in addition to some phenolic and carboxylic species observed at $\sim 150-160 \mathrm{ppm}$ and 165-180 ppm, respectively.

The solid state ${ }^{13} \mathrm{C}$ DPMAS NMR spectra of the different biochar samples enable the quantitative assessment of the changes in the biochar structure due to the presence of the mineral phases. The normalized ${ }^{13} \mathrm{C}$ NMR intensities are plotted against the pyrolysis temperatures for the different biochars and are shown in supplementary information Figure S1. The data indicate that the BKF and BBF biochars generally have a higher fraction of non-protonated aromatic carbon as compared to the total carbon, with the BBF550 biochar having the highest concentration. This implies that the BBF and BKF series of biochar have a greater degree of aromatic condensation that is correlated to greater stability of the biochar within the soil..$^{27-28}$ Additionally, the BBF and BKF series also have a higher concentration of phenolic species, particularly at $450{ }^{\circ} \mathrm{C}$ and $550{ }^{\circ} \mathrm{C}$

The overall effect of the pyrolysis temperature and the presence of clay on the biochar is better visualized by plotting the $\mathrm{O}: \mathrm{C} v s . \mathrm{H}: \mathrm{C}$ atomic ratios along the $\mathrm{x}$ and $\mathrm{y}$ axes respectively, for each pyrolysis temperature, as shown in Figure 3. The ratios are extracted directly from the data in Figure S1, which gives the ratios of the different $\mathrm{C}-\mathrm{H}, \mathrm{C}-\mathrm{O}$ and quaternary $\mathrm{C}$ species in the biochar. Figure 3 indicates that the evolution of the biochar is very dependent on the presence of the clay mineral during pyrolysis and that this effect is 
more pronounced at the lower temperatures. At lower temperatures, $\left(250^{\circ} \mathrm{C}\right)$, the $\mathrm{BKF}$ and $\mathrm{BBF}$ biochars have an increased amount of oxygen and a reduced amount of hydrogen as compared to the biochar without clay. At the intermediate temperatures, $\left(350{ }^{\circ} \mathrm{C}\right.$ to $\left.450{ }^{\circ} \mathrm{C}\right)$ the compositions of the BKF and BBF biochars deviate the most from BC biochar. Specifically, the presence of mineral species suppresses the removal of the oxygen moieties, while enhancing the removal of the hydrogen moieties. This results in biochar with a greater degree of aromatic condensation albeit with increased oxygen (acidic and phenolic) functionality. At the highest temperature $\left(550{ }^{\circ} \mathrm{C}\right)$ the different biochars yield very similar molecular compositions. This similarity can be seen as a strong indicator that the clay-mineral exerts a catalytic influence on the structure of the evolving biochar by lower the free energy for the condensation reactions (particularly at the lower temperatures). We hypothesize that since reaction rates are an exponential function of temperature, at the increased temperature $\left(550^{\circ} \mathrm{C}\right)$, condensed biochar structures similar to what would be expected from a catalyzed process should be formed. Further kinetic strudies need to undertake to confirm this.. With respect to the stability of the biochar, Figure 3 indicates that the bentonite-char yields the most condensed and therefore most stable material, while the biochars without clay and with kaolinite are very similar (at 550 ${ }^{\circ} \mathrm{C}$ ). These differences can be related to the dramatic changes in the structure of the clay (vide infra) with increase in the pyrolysis temperature ${ }^{39}$.

Inclusion and nature of the iron-bearing phases in the biochar. The intensity of the ${ }^{13} \mathrm{C}$ spinning sidebands $(s s b)$ gives an insight into the structure of the iron-bearing phases. Generally, in organic solids, the $s s b$ 's arise as a result of the MAS averaging out the chemical shift anisotropy (CSA), and occur at multiples of the spinning speed. Thus, a faster MAS results in smaller ssb's which are further away from the isotropic peaks. The full spinning sideband envelope for the ${ }^{13} \mathrm{C}$ NMR spectra is plotted in the supplementary information, Figure S2. For ${ }^{13} \mathrm{C}$ NMR, at the relatively low field strength (7 Tesla), and fast spinning (12 kHz MAS) conditions, we expect to see negligible, or very low intensity, first order $s s b$ 's, and this is indeed the case for the all the biochar pyrolyzed at $250{ }^{\circ} \mathrm{C}$ as well as the BC series pyrolyzed to higher temperatures (Supplementary information Figures S2 a$\mathrm{c}, \mathrm{d}, \mathrm{g}$ and $\mathrm{j}$ respectively). In contrast, the BBF biochars pyrolyzed at $450{ }^{\circ} \mathrm{C}$ and $550{ }^{\circ} \mathrm{C}$ 
have particularly high intensity $s s b$ 's, with fourth order $s s b$ 's being visible (supplementary information Figure S2, i and 1). Such unusually high intensity of the $s s b$ 's can be attributed to a paramagnetic induced anisotropy due to the formation of highly paramagnetic (superparamagnetic) phases in close (nanometer scale) proximity to the carbon structure of the biochar. It is well known that changes in the structure of iron oxides, such as $\mathrm{Fe}_{2} \mathrm{O}_{3}$, from the bulk scale (micron-sized or larger) to nano-scale results in their transition from a ferromagnetic to a super-paramagnetic state ${ }^{40}$. Indeed in Figure 1, the TEM images indicate that there are nano-scale iron-bearing phases within the porous structure of the biochar. Thus, intensity of the ssb signals in the ${ }^{13} \mathrm{C}$ solid state NMR particularly of the BBF at 450 ${ }^{\circ} \mathrm{C}$ and $550{ }^{\circ} \mathrm{C}$ indicate that the nano-sized iron phases are distributed fairly uniformly throughout the biochar. It is important to note that while both the bentonite and kaolinite clay slurries were prepared with iron sulfate, the strongest influence from the paramagnetic phases is observed with the biochar derived from the bentonite slurry-treated biomass. This implies that the specific presence of the bentonite clay acts as a catalyst for the formation of super-paramagnetic nano- $\mathrm{Fe}_{2} \mathrm{O}_{3}$ phases at temperatures above $450{ }^{\circ} \mathrm{C}$. Kaolin undergoes a structural transformation to metakaolinite in this temperature range and may not be able to exert a similar catalytic effect (Supplementary Figure S3 (e) and (f)).

Porosity of the biochar. The SEM and TEM (Figure 1) images show a complex porous structure of the biochar with multiple length scales. In order to quantify the porosity of the biochar, NMR cryoporometry was used and this yields the pore volume of the biochar samples as shown in Table 2, as well as the distribution of pore sizes as shown in Figure 4. This method has the additional and significant advantage of being applicable even when there are liquids and volatile components already in the pores. The porosity of the untreated bamboo biochar, $\mathrm{BC}($ Table 2$)$ follows the normal pattern of increased pore volume with pyrolysis temperature from $250{ }^{\circ} \mathrm{C}$ to $350{ }^{\circ} \mathrm{C}$, while above $350{ }^{\circ} \mathrm{C}$, the pore volume is nearly constant ${ }^{32}$. The lower pore volume at $250^{\circ} \mathrm{C}$ is attributable to hydrophobic volatiles formed from the biomass degradation, condensing into the pores of the forming biochar. ${ }^{41-}$ ${ }^{42}$ The BKF series of samples shows a contraction in pore volume at $450{ }^{\circ} \mathrm{C}$, which is possibly related to the decomposition of the cellulose and a much larger contraction at 550 ${ }^{\circ} \mathrm{C}$ where metakaolin can form. The loss of porosity of the BKF550 is directly correlated to 
the apparent collapse of the mesopore structure as seen by the very low mesoporosity in Figure 4 (b). The BBF series shows a decrease in pore volume as a function of temperature, but is significantly different to the BKF series. These differences are also observed with regards to the differences in the molecular structure of the carbon matrix as seen in Figure 2, and may be attributed to the difference in catalytic effect of the different clays as they interact with the biomass and inhomogeneous uptake of the clay and Fe on the surface. As the temperature increases, so the reaction between the iron, clays and the volatiles that are liberated accelerates. The data indicate that these complex reactions at higher temperatures lead to a closing of the sub-micron pores or at least to an occlusion of the access to the pore space.

The collapse of the mesopore volume for BKF550 biochar, as well as the molecular structure of BKF550 being very similar to the BC550, indicates that there is a change in the structure of the kaolinite clay. Evidence for this comes from examination of the thermally treated clay-iron mixtures by solid state ${ }^{29} \mathrm{Si}$ and ${ }^{27} \mathrm{Al}$ NMR of neat mixtures of clay and iron sulfate (supplementary information Figure S3). While the Fe/bentonite is stable to temperatures above $550{ }^{\circ} \mathrm{C}$, the Fe/kaolinite undergoes a degradation-transformation into metakaolin at $550{ }^{\circ} \mathrm{C}$. This thermal decomposition of kaolinite can explain the low porosity of the BKF550 biochar, as well as the results for the material in Figure 3. Below the thermal decomposition temperature of the kaolinite (i.e. at $450{ }^{\circ} \mathrm{C}$ ) both bentonite and kaolinite have high surface areas that we deduce results in producing biochars with similar structures. However, the metakaolinite formed at $550{ }^{\circ} \mathrm{C}$, has a low surface area and lacks the layered structure of kaolinite. The reduction in the porosity, specifically in the mesoporous regime, can be directly attributed to the metakaolinite blocking the mesoporous structure in the biochar. Concomitantly, the reduced surface area of the metakaolinite, and, hence, the reduced mineral-biochar interactions, significantly reduces the influence of the clay on the biochar structure. Therefore, the BKF biochar shifts to a structure very similar to that of the $\mathrm{BC}$ biochar. In contrast to the kaolinite, the bentonite clay does not undergo a structural collapse at $550{ }^{\circ} \mathrm{C}$ as suggested by ${ }^{29} \mathrm{Si}$ and ${ }^{27} \mathrm{Al} \mathrm{NMR}$, and continues to exert its influence through the high interfacial contact with the biochar. While this results in a biochar with a greater degree of molecular condensation, it also means that the pore structure of the bentonite impregnated biochar remains open and 
accessible for possible growth of beneficial microbes and root hairs.

Implications for the synthesis of engineered biochar. Previous work has demonstrated that properties of the biochar, such as the concentration of acidic functionalities, the degree of aromatic condensation and porosity of the biochar play key roles in determining its stability within the soil, its ability to enhance soil fertility and its capability for pollutant sequestration $^{7,17}$. Here, we provide quantitative measurements which demonstrate that the concentration of acidic functionalities (particularly the phenolic species), the degree of aromatic condensation and the pore volume of the engineered biochar can be controlled to a high degree by infiltrating the biomass with high surface area clay minerals and iron salts prior to pyrolysis. For example, primarily as a means for carbon sequestration, the BBF550 biochar would be the most suitable as it has highest degree of aromatic condensation which

enhances biochar stability within the soil ${ }^{5,28}$. On the other hand to enhance the soil fertility or immobilize soil contaminants, the BKF450 and BBF450 biochar with their higher concentration of phenolic and carboxylic species would be well suited. Furthermore, infiltration and formation of clay and metal oxide nanostructures within the pores of the biochar enhances the capability of these engineered biochars to promote redox reactions that have a significant impact on the health of the rhizosphere. Finally, it is important to note that the control of the biochar structure is enabled by use of materials which are inexpensive and naturally available across a wide geographical distribution. Detailed investigations of the composition, nanostructure and magnetic properties of the mineral phases will soon be forthcoming elsewhere. The next step will be to demonstrate the differences in the activity of these biochar materials under field conditions and correlate them to the molecular structure measured herein.

\section{Acknowledgments}

We acknowledge the assistance of the Electron Microscope and X-ray unit of University of Newcastle and the EMU and NMR Facility of the Mark Wainwright Analytical Centre, University of NSW. This work was supported by ARC grant LP120200418, Renewed Carbon Pty Ltd. and the DAFF Carbon Farming Futures Filling the Research Gap 
(RG134978). We acknowledge extensive discussions with Dr. Njegic for insightful comments regarding the manuscript.

\section{References}

1. Woolf, D.; Amonette, J. E.; Street-Perrott, F. A.; Lehmann, J.; Joseph, S., Sustainable biochar to mitigate global climate change. Nat. Commun. 2010, 1 (56).

2. Clare, A.; Barnes, A.; McDonagh, J.; Shackley, S., From rhetoric to reality: farmer perspectives on the economic potential of biochar in China. Int. J. Agr. Sustain. 2014, 12 (4), 440-458.

3. Kammann, C. I.; Schmidt, H.-P.; Messerschmidt, N.; Linsel, S.; Steffens, D.; Mueller, C.; Koyro, H.-W.; Conte, P.; Stephen, J., Plant growth improvement mediated by nitrate capture in co-composted biochar. Scientific Reports 2015, 5.

4. $\quad$ Blackwell, P.; Joseph, S.; Munroe, P.; Anawar, H. M.; Storer, P.; Gilkes, R. J.; Solaiman, Z. M., Influences of Biochar and Biochar-Mineral Complex on Mycorrhizal Colonisation and Nutrition of Wheat and Sorghum. Pedosphere 2015, 25 (5), 686-695.

5. Singh, B. P.; Cowie, A. L.; Smernik, R. J., Biochar carbon stability in a clayey soil as a aunction of feedstock and pyrolysis temperature. Environ. Sci. Technol. 2012, 46 (21), 11770-11778.

6. Harvey, O. R.; Kuo, L. J.; Zimmerman, A. R.; Louchouarn, P.; Amonette, J. E.; Herbert, B. E., An Index-Based Approach to Assessing Recalcitrance and Soil Carbon Sequestration Potential of Engineered Black Carbons (Biochars). Environ. Sci. Technol. 2012, 46 (3), 1415-1421.

7. Atkinson, C. J.; Fitzgerald, J. D.; Hipps, N. A., Potential mechanisms for achieving agricultural benefits from biochar application to temperate soils: a review. Plant Soil 2010, 337 (1-2), 1-18.

8. Clare, A.; Shackley, S.; Joseph, S.; Hammond, J.; Pan, G.; Bloom, A., Competing uses for China's straw: the economic and carbon abatement potential of biochar. Global Change Biology Bioenergy 2015, 7 (6), 1272-1282.

9. Roberts, K. G.; Gloy, B. A.; Joseph, S.; Scott, N. R.; Lehmann, J., Life Cycle Assessment of Biochar Systems: Estimating the Energetic, Economic, and Climate Change Potential. Environmental Science \& Technology 2010, 44 (2), 827-833.

10. Shackley, S.; Clare, A.; Joseph, S.; McCarl, B.; Schmidt, H.-P., Economic evaluation of biochar systems: : current evidence and challenges In Biochar for Environmental Management : Science, Technology and Implementation, 2 ed.; Lehmann, J.; Joseph, S., Eds. Taylor \& Francis: London and New York, 2015; Vol. 1, pp 813-851. 11. Joseph, S.; van Zwieten, L.; Chia, C. H., "Designing" of Biochar for Specific Applications to Soils; A Technology in Its Infancy. In Biochar and Soil Biota, Ladygina, N.; Rineau, F., Eds. CRC Press: Boca Raton, 2013.

12. Novak, J. M.; Lima, I. M.; Xing, B.; Gaskin, J. W.; Steiner, C.; Das, K. C.; Ahmedna, M.; Rehrah, D.; Watts, D. W.; Busscher, W. J.; Schomberg, H., Characterization of designer biochar produced at different temperatures and their effects on a loamy sand. Ann. Environ. Sci. 2009, 3, 195-206.

13. Nielsen, S.; Minchin, T.; Kimber, S.; van Zwieten, L.; Gilbert, J.; Munroe, P.; Joseph, S.; Thomas, T., Comparative analysis of the microbial communities in agricultural soil amended with enhanced biochars or traditional fertilisers. Agric. Ecosyst. Environ. 2014, 191, 73-82. 
14. Chia, C. H.; Singh, B. P.; Joseph, S.; Graber, E. R.; Munroe, P., Characterization of an enriched biochar. J. Anal. Appl. Pyrolysis 2014, 108, 26-34.

15. Yao, C.; Joseph, S.; Li, L.; Pan, G.; Lin, Y.; Munroe, P.; Pace, B.; Taherymoosavi, S.; Van Zwieten, L.; Thomas, T.; Nielsen, S.; Ye, J.; Donne, S., Developing More Effective Enhanced Biochar Fertilisers for Improvement of Pepper Yield and Quality.

Pedosphere 2015, 25 (5), 703-712.

16. Joseph, S.; Anawar, H. M.; Storer, P.; Blackwell, P.; Chia, C.; Lin, Y.; Munroe, P.; Donne, S.; Horvat, J.; Wang, J.; Solaiman, Z. M., Effects of Enriched Biochars Containing Magnetic Iron Nanoparticles on Mycorrhizal Colonisation, Plant Growth, Nutrient Uptake and Soil Quality Improvement. Pedosphere 2015, 25 (5), 749-760.

17. Joseph, S.; Graber, E. R.; Chia, C.; Munroe, P.; Donne, S.; Thomas, T.; Nielsen, S.; Marjo, C.; Rutlidge, H.; Pan, G. X.; Li, L.; Taylor, P.; Rawal, A.; Hook, J., Shifting paradigms: development of high-efficiency biochar fertilizers based on nano-structures and soluble components. Carbon Manag. 2013, 4 (3), 323-343.

18. Li, Y.; Yu, S.; Strong, J.; Wang, H., Are the biogeochemical cycles of carbon, nitrogen, sulfur, and phosphorus driven by the "Fe-III-Fe-II redox wheel" in dynamic redox environments? J. Soils Sediments 2012, 12 (5), 683-693.

19. http://www.biocharinternational.org/sites/default/files/IBI_Biochar_Standards_V2\%200_final_2014.pdf. 20. Yao, Y.; Gao, B.; Fang, J.; Zhang, M.; Chen, H.; Zhou, Y.; Creamer, A. E.; Sun, Y.; Yang, L., Characterization and environmental applications of clay-biochar composites. Chem. Eng. J. 2014, 242, 136-143.

21. Chen, Y.-X.; Huang, X.-D.; Han, Z.-Y.; Huang, X.; Hu, B.; Shi, D.-Z.; Wu, W.-X., Effects of bamboo charcoal and bamboo vinegar on nitrogen conservation and heavy metals immobility during pig manure composting. Chemosphere 2010, 78 (9), 1177-1181. 22. Brewer, C. E.; Schmidt-Rohr, K.; Satrio, J. A.; Brown, R. C., Characterization of biochar from fast pyrolysis and gasification systems. Environ. Prog. Sustain. 2009, 28 (3), 386-396.

23. Keiluweit, M.; Nico, P. S.; Johnson, M. G.; Kleber, M., Dynamic molecular structure of plant biomass-derived black carbon (biochar). Environ. Sci. Technol. 2010, 44 (4), 1247-1253.

24. Wang, S.; Gao, B.; Zimmerman, A. R.; Li, Y.; Ma, L.; Harris, W. G.; Migliaccio, K. W., Removal of arsenic by magnetic biochar prepared from pinewood and natural hematite. Bioresour. Technol. 2015, 175, 391-395.

25. Wang, S.; Gao, B.; Li, Y.; Mosa, A.; Zimmerman, A. R.; Ma, L. Q.; Harris, W. G.; Migliaccio, K. W., Manganese oxide-modified biochars: Preparation, characterization, and sorption of arsenate and lead. Bioresour. Technol. 2015, 181, 13-17.

26. Li, F.; Cao, X.; Zhao, L.; Wang, J.; Ding, Z., Effects of Mineral Additives on Biochar Formation: Carbon Retention, Stability, and Properties. Environmental Science \& Technology 2014, 48 (19), 11211-11217.

27. McBeath, A. V.; Smernik, R. J.; Schneider, M. P. W.; Schmidt, M. W. I.; Plant, E. L., Determination of the aromaticity and the degree of aromatic condensation of a thermosequence of wood charcoal using NMR. Org. Geochem. 2011, 42 (10), 1194-1202. 28. Zimmerman, A. R.; Gao, B., The Stability of Biochar in the Environment: Introduction. CRC Press: Boca Raton, Fl, 2013; p 1-40.

29. ASTM D7582. http://www.astm.org/Standards/D7582.htm. 
30. D4326, A. http://www.astm.org/Standards/D4326.htm.

31. Torchia, D. A., Measurement of proton-enhanced C-13 T1 values by a method which suppresses artifacts J. Magn. Reson. 1978, 30 (3), 613-616.

32. Webber, J. B. W.; Corbett, P.; Semple, K. T.; Ogbonnaya, U.; Teel, W. S.;

Masiello, C. A.; Fisher, Q. J.; Valenza, J. J.; Song, Y. Q.; Hu, Q. H., An NMR study of porous rock and biochar containing organic material. Microporous Mesoporous Mater. 2013, 178, 94-98.

33. Coombs, P. G.; Munir, Z. A., The decomposition of iron(III) sulfate in air. $J$. Therm. Anal. 1989, 35 (3), 967-976.

34. Choudalakis, G.; Gotsis, A. D., Permeability of polymer/clay nanocomposites: A review. Eur. Polym. J. 2009, 45 (4), 967-984.

35. Rocchi, D.; Gonzalez, J. F.; Menendez, J. C., Montmorillonite Clay-Promoted, Solvent-Free Cross-Aldol Condensations under Focused Microwave Irradiation. Molecules 2014, 19 (6), 7317-7326.

36. Varma, R. S., Clay and clay-supported reagents in organic synthesis. Tetrahedron 2002, 58 (7), 1235-1255.

37. Nagendrappa, G., Organic synthesis using clay and clay-supported catalysts. Applied Clay Science 2011, 53 (2), 106-138.

38. Anjum, R.; Krakat, N.; Reza, M. T.; Klocke, M., Assessment of mutagenic potential of pyrolysis biochars by Ames Salmonella/mammalian-microsomal mutagenicity test. Ecotoxicology and Environmental Safety 2014, 107, 306-312.

39. Meinhold, R. H.; Mackenzie, K. J. D.; Brown, I. W. M., Thermal-reactions of kaolinite studied by solid-state 2-Al and 29-Si NMR. J. Mater. Sci. Lett. 1985, 4 (2), 163 166.

40. Kucheryavy, P.; He, J.; John, V. T.; Maharjan, P.; Spinu, L.; Goloverda, G. Z.; Kolesnichenko, V. L., Superparamagnetic iron oxide nanoparticles with variable size and an iron oxidation state as prospective imaging agents. Langmuir 2013, 29 (2), 710-716.

41. Park, J.; Hung, I.; Gan, Z.; Rojas, O. J.; Lim, K. H.; Park, S., Activated carbon from biochar: Influence of its physicochemical properties on the sorption characteristics of phenanthrene. Bioresour. Technol. 2013, 149, 383-389.

42. Zhang, J. N.; Lu, F.; Zhang, H.; Shao, L. M.; Chen, D. Z.; He, P. J., Multiscale visualization of the structural and characteristic changes of sewage sludge biochar oriented towards potential agronomic and environmental implication. Scientific Reports 2015, 5. 


\begin{tabular}{|c|c|c|c|c|c|c|c|c|c|c|c|c|}
\hline Sample & $\begin{array}{c}\text { Pyrolysis } \\
\text { temp. }\end{array}$ & Minerals & Yield $\%$ & $\mathrm{C} \%$ & $\mathrm{H} \%$ & $\mathrm{~N} \%$ & $\mathrm{~S} \%$ & $\mathrm{Fe} \%$ & $\mathrm{Al} \%$ & $\mathrm{Ca} \%$ & $\mathrm{~K} \%$ & Ash \% \\
\hline BC250 & $250{ }^{\circ} \mathrm{C}$ & - & 78 & 51.9 & 5.45 & 0.87 & 0.08 & 0.014 & 0.0016 & 0.050 & 0.83 & 14.38 \\
\hline BC350 & $350{ }^{\circ} \mathrm{C}$ & - & 60 & 71.5 & 4.02 & 1.11 & 0.07 & 0.011 & 0.0022 & 0.075 & 1.4 & 28.08 \\
\hline BC450 & $450{ }^{\circ} \mathrm{C}$ & - & 35 & 75 & 3.42 & 1.38 & 0.12 & 0.023 & 0.0051 & 0.098 & 1.4 & 19.10 \\
\hline BC550 & $550{ }^{\circ} \mathrm{C}$ & - & 33 & 79.2 & 2.72 & 1.28 & 0.06 & 0.030 & 0.0050 & 0.078 & 0.85 & 26.34 \\
\hline & & & & & & & & & & & & \\
\hline BKF250 & $250{ }^{\circ} \mathrm{C}$ & $\mathrm{FeSO}_{4}+\mathrm{Kao}$. & 86 & 48.7 & 5.15 & 0.5 & 1.0 & 2.0 & 0.026 & 0.046 & 0.74 & 15.43 \\
\hline BKF350 & $350{ }^{\circ} \mathrm{C}$ & $\mathrm{FeSO}_{4}+\mathrm{Kao}$. & 59 & 67.6 & 3.3 & 0.87 & 1.1 & 2.1 & 0.042 & 0.054 & 1.0 & 11.40 \\
\hline BKF450 & $450{ }^{\circ} \mathrm{C}$ & $\mathrm{FeSO}_{4}+\mathrm{Kao}$. & 48 & 62.9 & 2.82 & 1.45 & 1.1 & 2.9 & 0.093 & 0.069 & 1.2 & 35.60 \\
\hline BKF550 & $550{ }^{\circ} \mathrm{C}$ & $\mathrm{FeSO}_{4}+\mathrm{Kao}$. & 38 & 63.6 & 1.72 & 1.39 & 0.52 & 2.3 & 0.16 & 0.049 & 0.64 & 14.61 \\
\hline & & & & & & & & & & & & \\
\hline BBF250 & $250{ }^{\circ} \mathrm{C}$ & $\mathrm{FeSO}_{4}+\mathrm{Ben}$. & 76 & 48.7 & 5.15 & 0.5 & 0.73 & 1.2 & 0.010 & 0.053 & 0.35 & 15.91 \\
\hline BBF350 & $350{ }^{\circ} \mathrm{C}$ & $\mathrm{FeSO}_{4}+\mathrm{Ben}$. & 63 & 57.2 & 3.51 & 0.8 & 1.4 & 2.5 & 0.029 & 0.12 & 0.82 & 24.14 \\
\hline BBF450 & $450{ }^{\circ} \mathrm{C}$ & $\mathrm{FeSO}_{4}+\mathrm{Ben}$. & 42 & 61 & 2.79 & 0.84 & 1.3 & 2.5 & 0.034 & 0.12 & 0.63 & 56.87 \\
\hline BBF550 & $550{ }^{\circ} \mathrm{C}$ & $\mathrm{FeSO}_{4}+\mathrm{Ben}$. & 38 & 70.2 & 2.49 & 0.79 & 0.63 & 1.7 & 0.10 & 0.10 & 0.37 & 31.64 \\
\hline
\end{tabular}

Table 1. Composition (weight \%) of the biochar materials by ASTM D7582 29 and ASTM D $4326^{30}$. Kao. refers to kaolinite and Ben refers to bentonite 


\begin{tabular}{|c|c|c|c|}
\hline $\begin{array}{c}\text { Pyrolysis } \\
\text { Temperature } \\
{ }^{\circ} \mathrm{C}\end{array}$ & $\begin{array}{c}\text { BC series of } \\
\text { biochar } \\
\left(\text { Pore vol ml. }^{-1}\right)\end{array}$ & $\begin{array}{c}\text { BKF series of } \\
\text { biochar } \\
\left(\text { Pore vol ml.g }^{-1}\right)\end{array}$ & $\begin{array}{c}\text { BBF series of } \\
\text { biochar } \\
\left(\text { (ore vol ml.g }^{-1}\right)\end{array}$ \\
\hline 250 & 0.36 & 0.73 & 0.88 \\
\hline 350 & 1.05 & 0.86 & 0.77 \\
\hline 450 & 0.77 & 0.56 & 0.73 \\
\hline 550 & 1.01 & 0.16 & 0.42 \\
\hline
\end{tabular}

Table 2. Pore Volume as a function of temperature and clay treatment from the NMR cryoporosimetry. Error bar for the measurements is $\pm 0.15 \mathrm{ml} / \mathrm{g}$ 

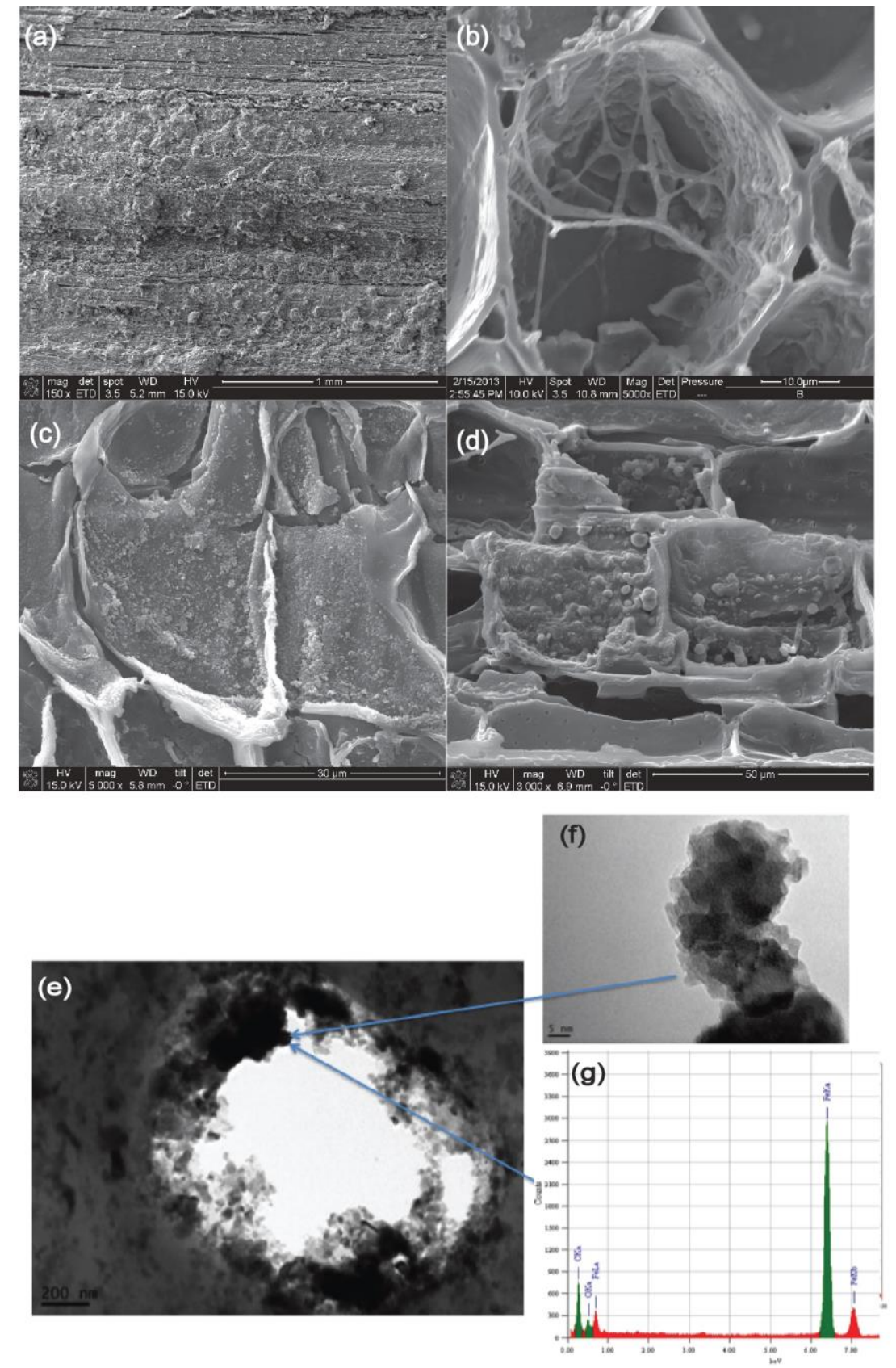

Figure 1. SEM images of BKF550 biochar (a), BKF450 biochar (b), BBC550 biochar (c) and BBC450 biochar (d). The TEM image of a macropore of BKF550 (e) shows there are a range of minerals (dark phases) both in the mesopores of the amorphous carbon lattice and on the surface. TEM image of the nanostructured mineral decorating in the inner pore surface (f). TEM-EDS spectra of the nanostructured mineral identifying it as a Fe-rich mineral (g). 

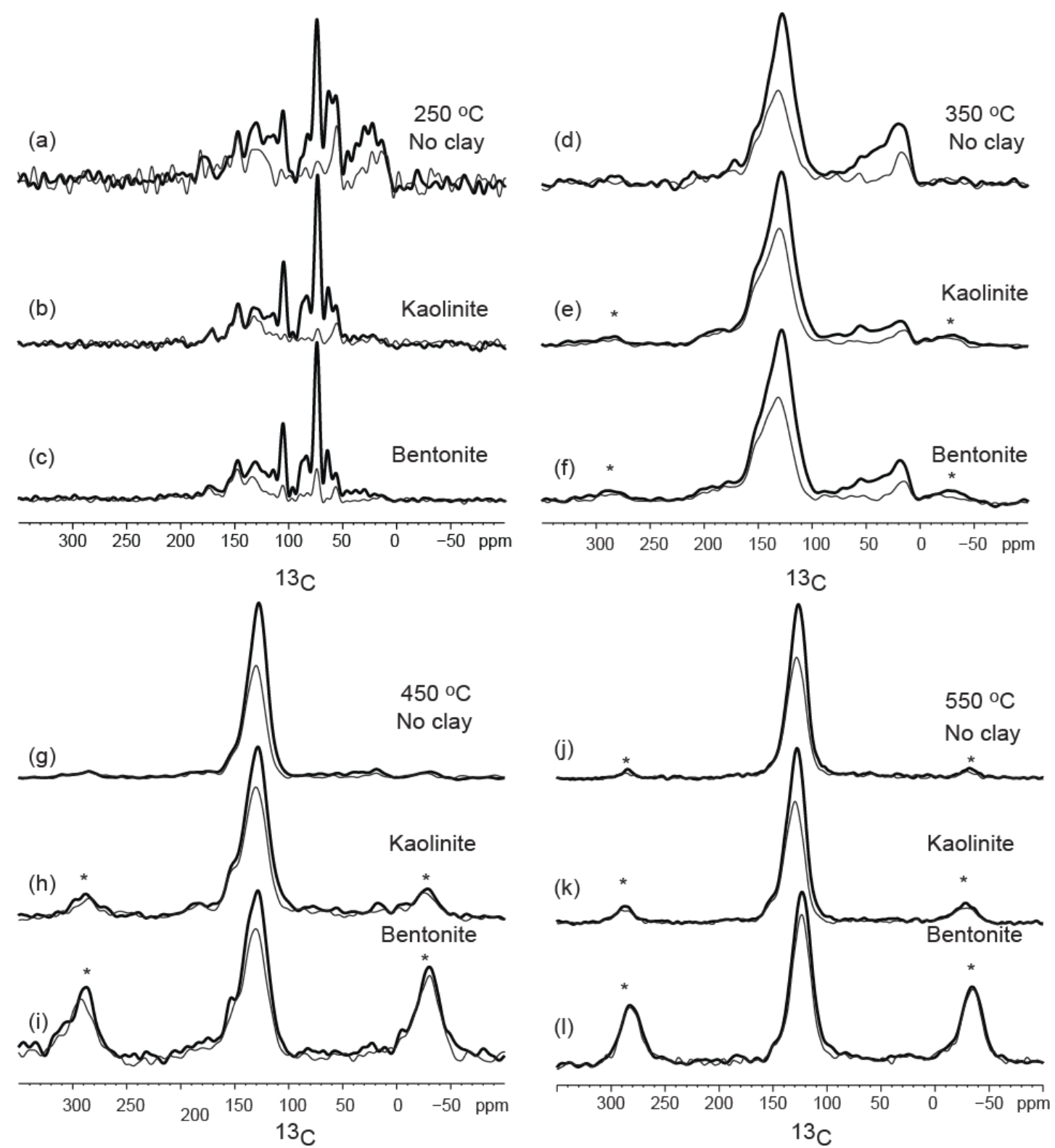

Figure 2. Quantitative ${ }^{13} \mathrm{C}$ DP MAS NMR spectra of the BC biochar series (a, $d, g$, and $j$ ), the BKF biochar series (b, e, h, and k) and the BBF biochar series (c, f, i, and l). The spectra of the chars are quantitatively measured by ${ }^{13} \mathrm{C}$ DPMAS NMR. The spectra plotted in bold lines represent the total ${ }^{13} \mathrm{C}$ NMR signal while the spectra plotted in thin line were acquired after $67 \mu$ s of recoupled dipolar dephasing and represent the signal of the nonprotonated carbon species. The difference between the bold and narrow spectra represents the amount of protonated carbon species. * represents the spinning sidebands 


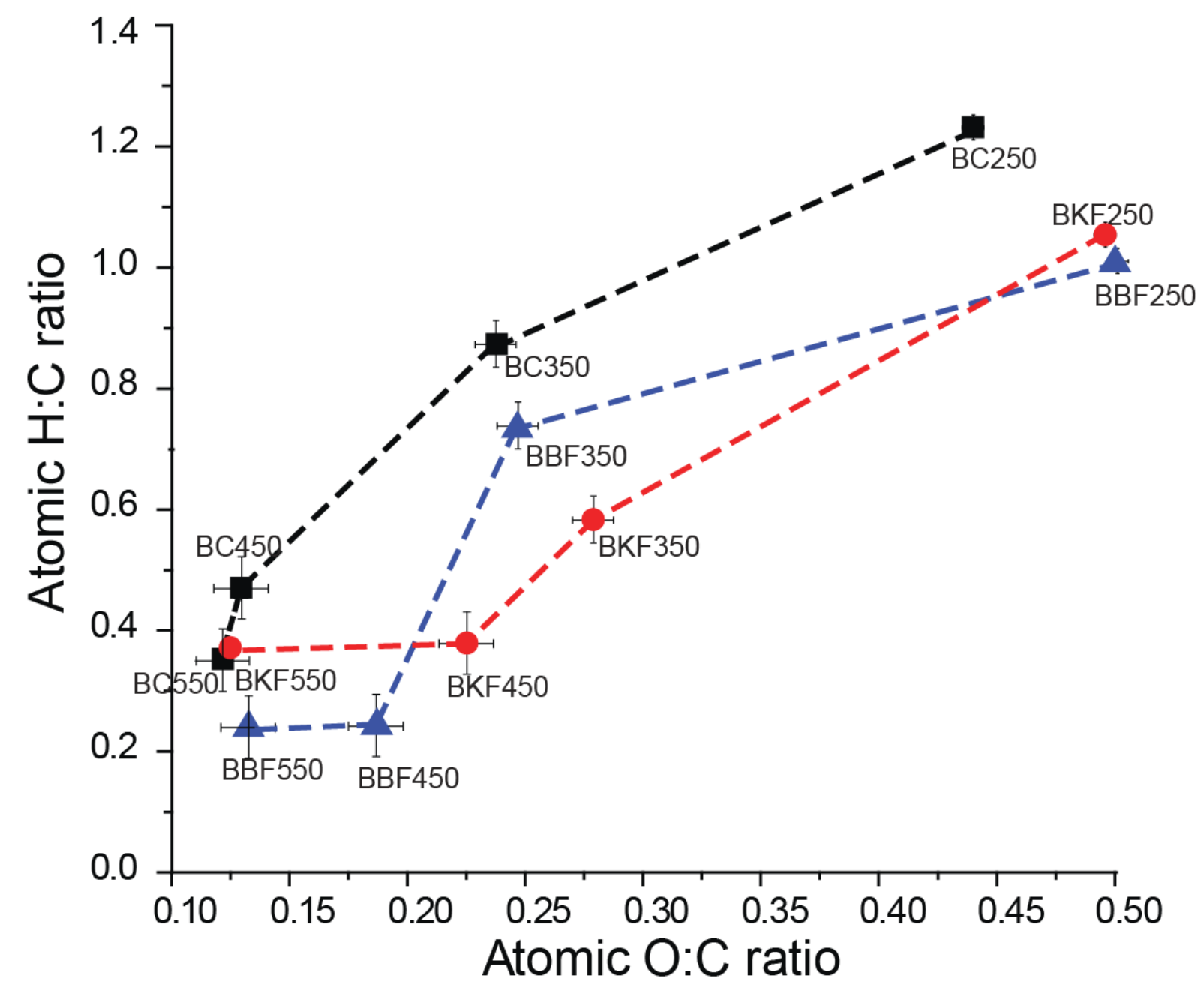

Figure 3. Correlation of $\mathrm{H}: \mathrm{C}$ and $\mathrm{O}: \mathrm{C}$ atomic ratios for the $\mathrm{BC}$ biochar series (squares), the BKF biochar series (circles) and the BBF biochar series (triangles). The dashed lines are guides to the eye. 

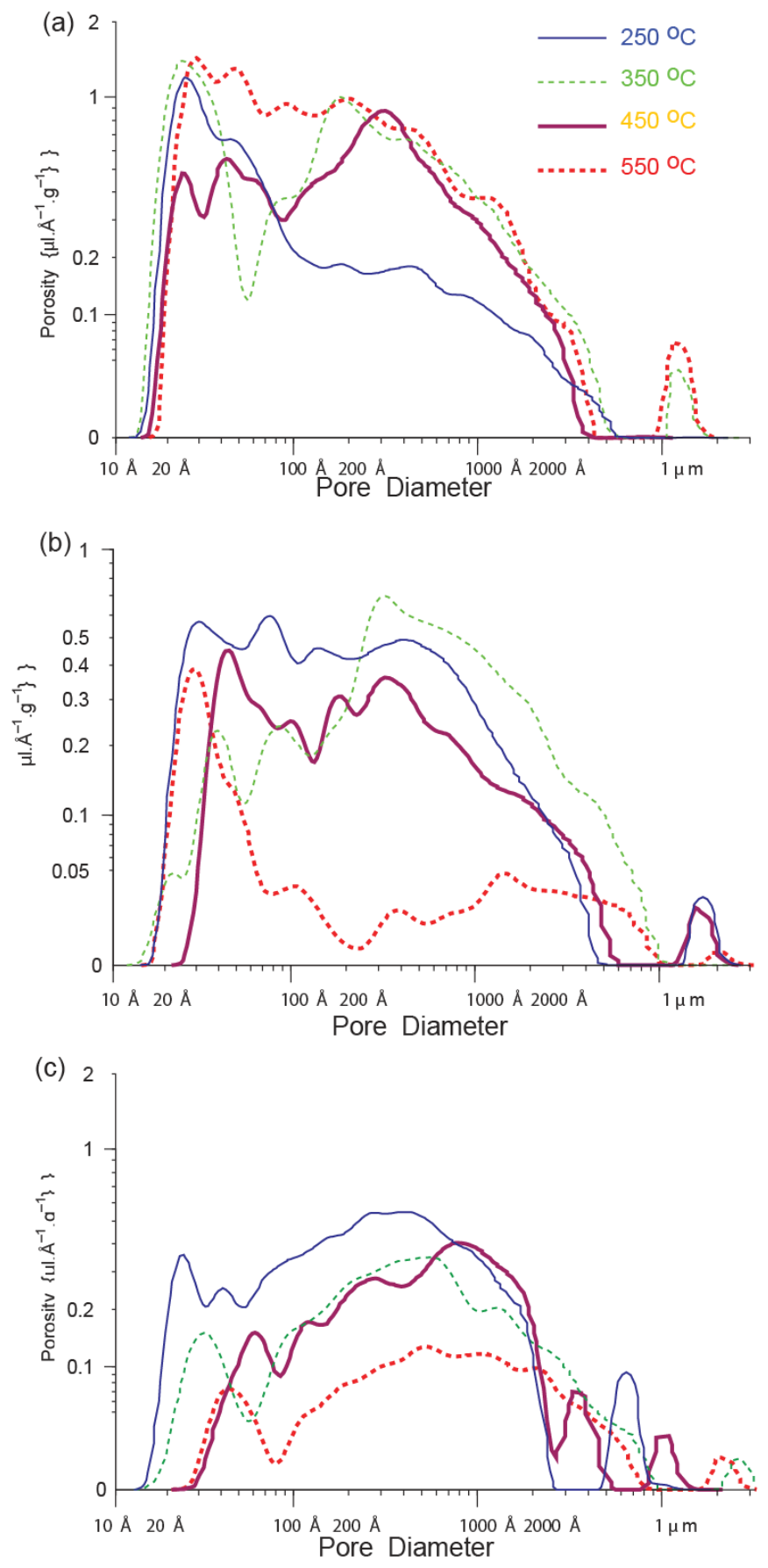

Figure 4. Porosity as a function of pore diameter for BC biochar (a), BKF biochar (b) and BBF biochar (c) as measured by NMR cryo-porosimetry. The curves are for biochars pyrolyzed at $250{ }^{\circ} \mathrm{C}$ (thin line), $350{ }^{\circ} \mathrm{C}$ thin dashed line, $450{ }^{\circ} \mathrm{C}$ bold line and $550{ }^{\circ} \mathrm{C}$ (bold dashed line). 


\section{Supplementary Information}
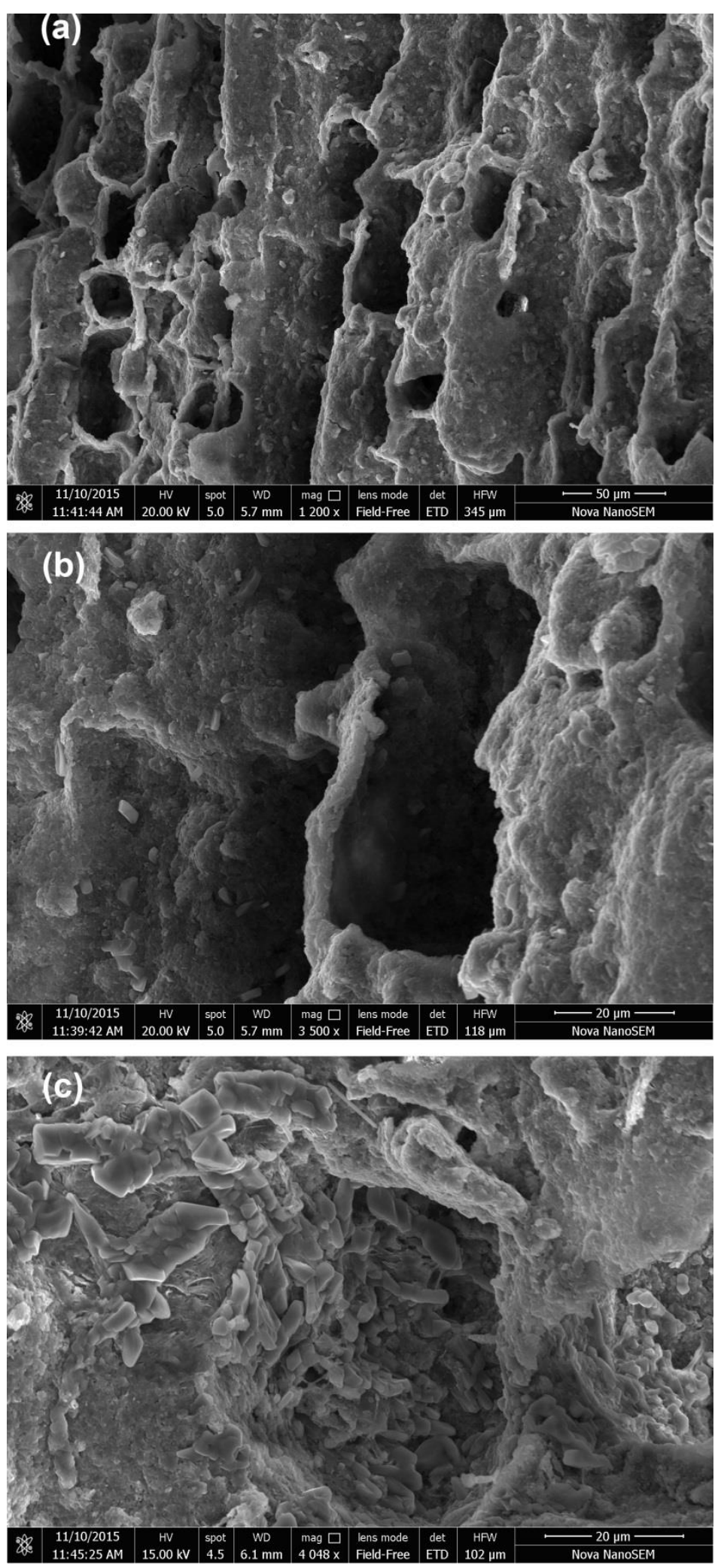

Page 23 of 36 
Figure S1. SEM micrographs of BKF250 biochar at (a) $1200 \mathrm{x}$, (b) $3500 \mathrm{x}$ and (c) $4018 \times$ magnification. Figure (a) shows the porous surface-structure of the biochar (b) shows a close up of a surface pore, showing small mineral inclusions. (c) Shows a surface pore covered by the clay-mineral mixture. 

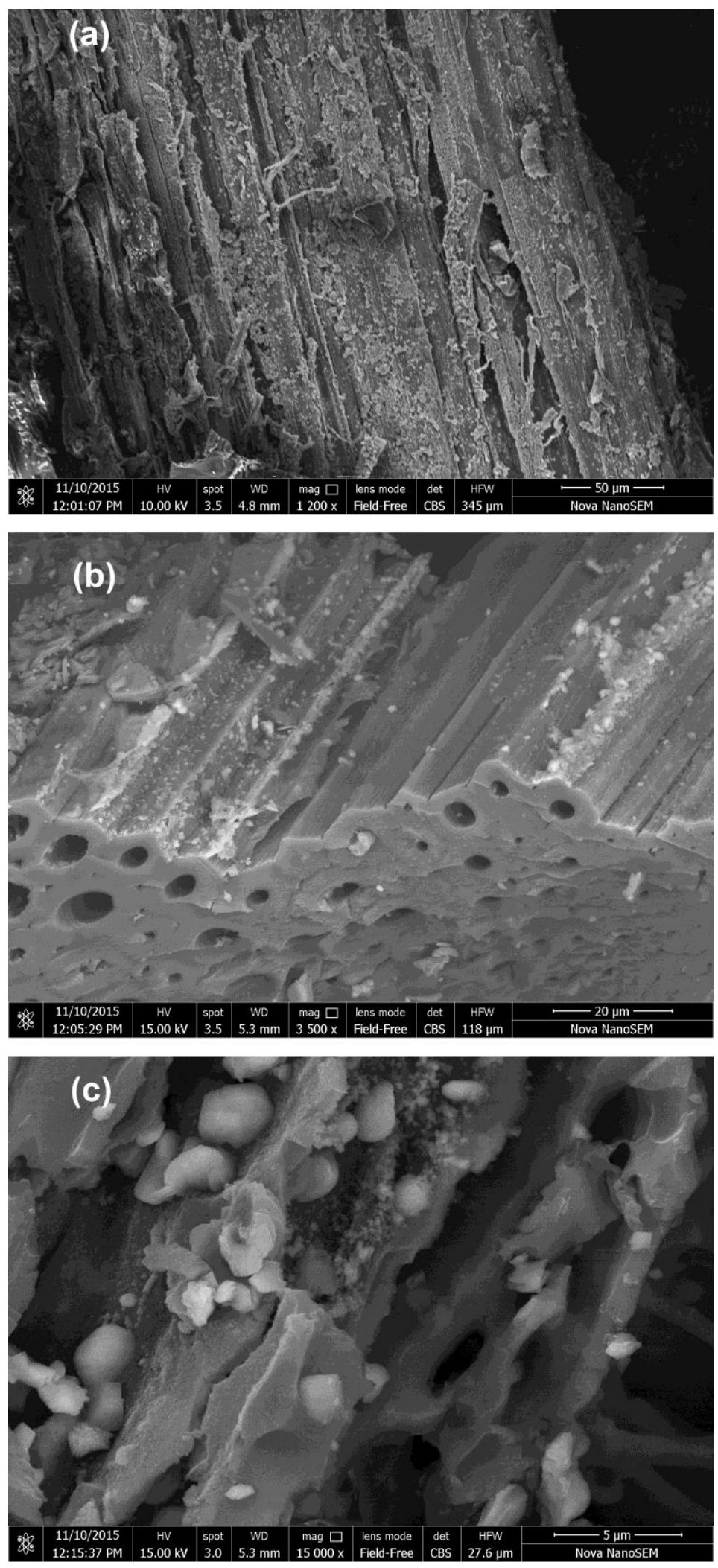

Figure S2. SEM micrographs of BBF250 biochar at (a) $1200 \mathrm{x}$, (b) $3500 \mathrm{x}$ and (c) $1500 \times$ magnification. Figure (a) shows a fibrous surface-structure of the bamboo 
biochar covered by the clay- mineral. (b) shows an edge view with the open pores at one end with some clay-mineral inclusions. (c) Shows a zoomed in view of the surface decorated with micron and sub-micron sized mineral particles. 

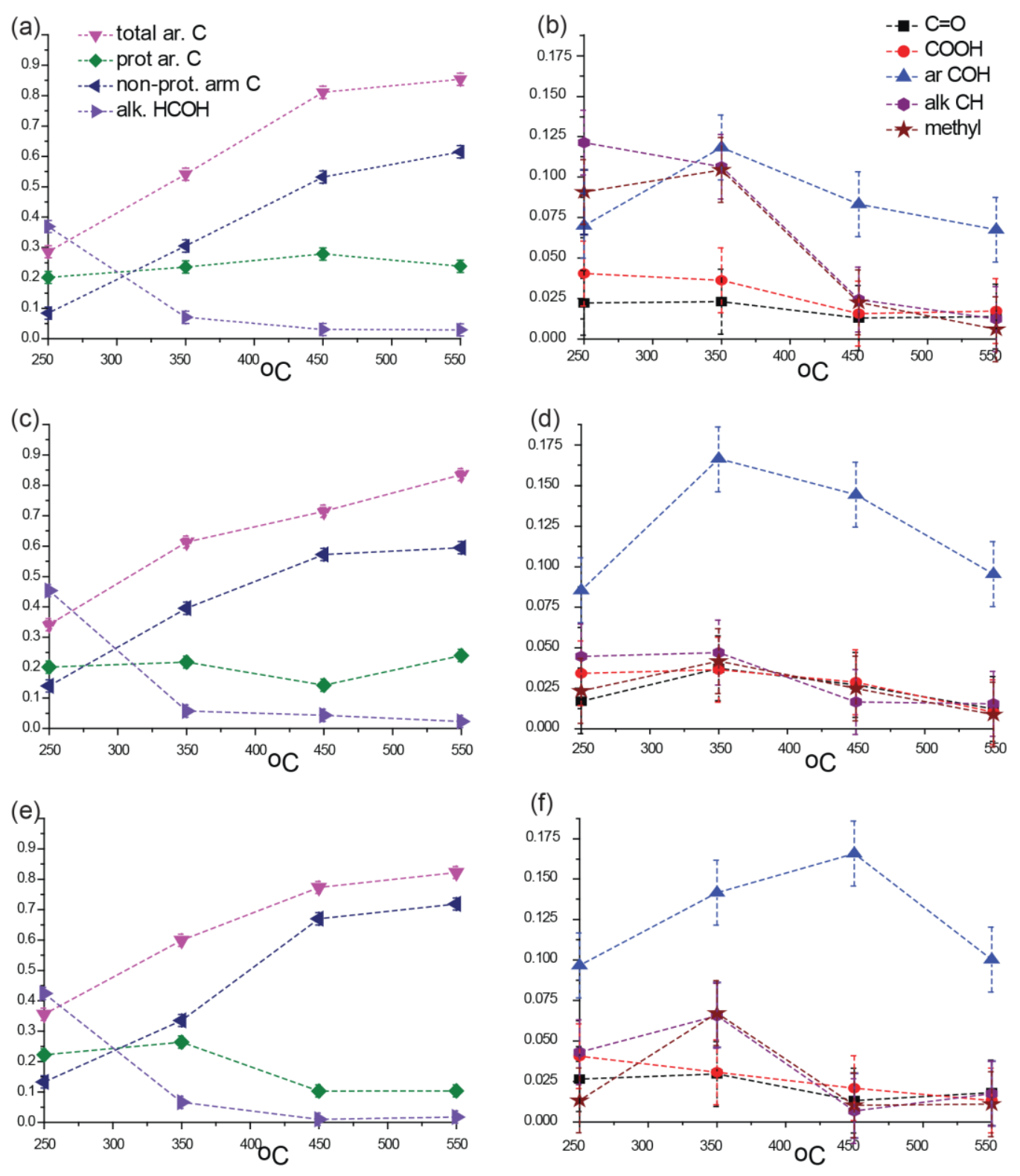

Figure S2. Plots of the variation of concentrations of the different carbon functional groups as a function of temperature, for the BC series (figures $a$ and $b$ ), the BKF series (figure $c$ and $d$ ) and the BBF series (figure $e$ and $f$ ). The values have been normalized to the NMR signal area of all the carbon. The dashed lines are guides to the eye. ar. $\mathrm{C}$ is the aromatic carbon. prot. ar. $\mathrm{C}$ is the protonated aromatic carbon, non-prot arm. $\mathrm{C}$ is the non-protonated aromatic carbon, alk. $\mathrm{HCOH}$ is are alkyl $\mathrm{HCOS}$ species, ar. $\mathrm{COH}$ are the phenolic species, alk $\mathrm{CH}$ are the alkyl $\mathrm{CH}$ and $\mathrm{CH} 2$ species. 


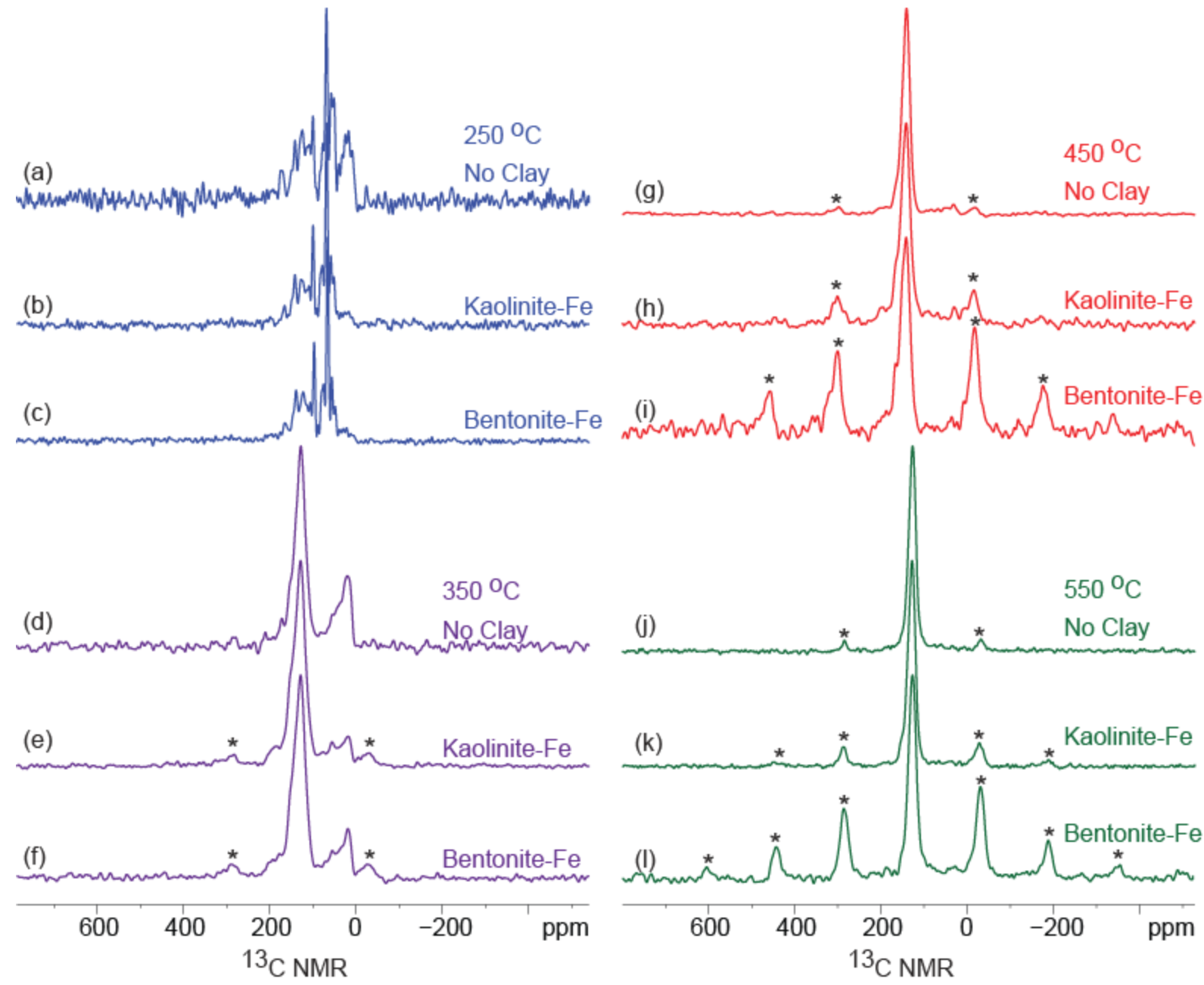

Figure S3. 13C DPMAS NMR of biochar showing the full manifold of the spinning side bands. The spinning side bands are marked by * 

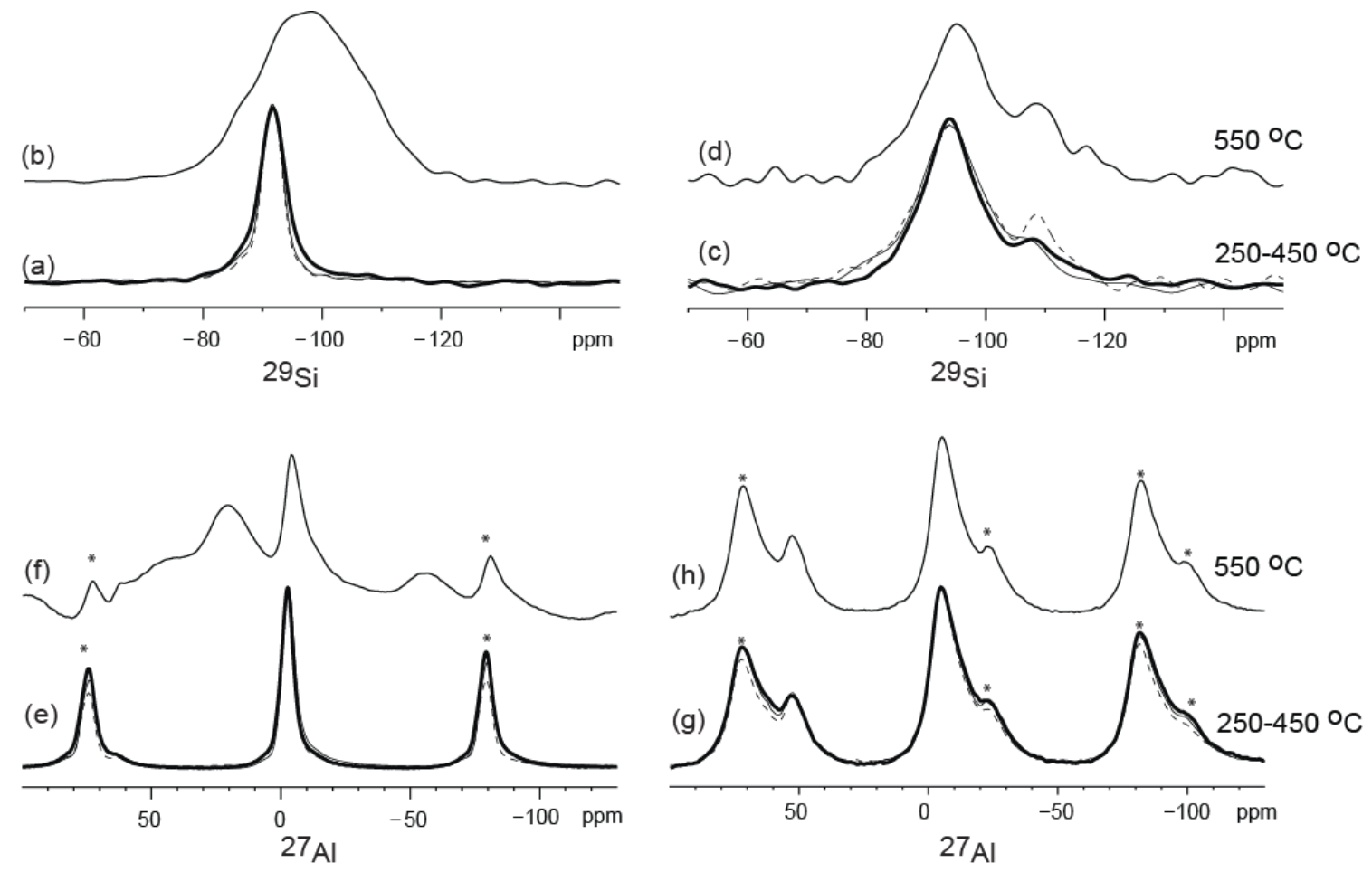

Figure S4. 29Si and 27Al solid state NMR spectra of Kaolinite+FeSO4 (a-b and ef) and Bentonite $+\mathrm{FeSO} 4$ (c-d and g-h). (a), (c), (e) and (g) show overlay of spectra of material heated to $250^{\circ} \mathrm{C}$ (bold line), $350^{\circ} \mathrm{C}$ (bold dashed line) and $450{ }^{\circ} \mathrm{C}$ (thin dashed line). (b), (d), (f) and (h) are the spectra acquired after heating to $550^{\circ} \mathrm{C}$.

Sample preparation. The clay $\mathrm{FeSO}_{4}$ slurries were dried to yield a uniform mixture. These mixtures were pyrolyzed upto $550^{\circ} \mathrm{C}$ following the same procedures as used for the synthesis of the biochars. The heat treated clay+FeSO ${ }_{4}$ samples were packed into $4 \mathrm{~mm}$ and $7 \mathrm{~mm}$ zirconia rotors with Kel-F caps for solid state NMR analysis. The ${ }^{29} \mathrm{Si}$ solid state NMR experiments were carried out on Bruker AVANCE III 300 spectrometer with a 7 Tesla super conducting magnet operating at frequencies of $300 \mathrm{MHz}$ and $59.5 \mathrm{MHz}$ for the ${ }^{1} \mathrm{H}$ and ${ }^{29} \mathrm{Si}$ nuclei respectively. The ${ }^{29} \mathrm{Si}$ measurements of the thermally treated clays were carried out in a $7 \mathrm{~mm}$ $\mathrm{HX}$ double resonance probe at $6.5 \mathrm{kHz} \mathrm{MAS},{ }^{29} \mathrm{Si} 90^{\circ}$ pulse length of $6.5 \mu \mathrm{s}$, with recycle delays of $1 \mathrm{~s}, 55 \mathrm{kHz}{ }^{1} \mathrm{H}$ SPINAL64 decoupling and with $4 \mathrm{k}$ transients co- 
added for signal averaging. The ${ }^{27} \mathrm{Al}$ NMR spectra of the thermally treated clays were measured on a Bruker AVANCE III 700 spectrometer with a 16.4 Tesla superconducting magnet operating at frequencies of $700 \mathrm{MHz}$ and $182.5 \mathrm{MHz}$ for $1 \mathrm{H}$ and $27 \mathrm{Al}$ respectively. The ${ }^{27} \mathrm{Al}$ spectra were acquired at $14 \mathrm{kHz}$ MAS with a single pulse experiment, with a $2.2 \mu \mathrm{s} 90^{\circ}$ pulse length, $1 \mathrm{~s}$ recycle delay and 512 transients for signal averaging. We note that the NMR spectra of the kaolinite change at $550^{\circ} \mathrm{C}$ due to its structural transformation into meta-kaolinite. There is a slight changed in the ${ }^{27} \mathrm{Al}$ and ${ }^{29} \mathrm{Si}$ spectra of the bentonite at $550{ }^{\circ} \mathrm{C}$ as compared to the lower temperatures. However this change is attributed to the broadening effect of the super-paramagnetic -iron bearing phase formed at the elevated temperatures rather than a change in the structure of the bentonite clay itself.

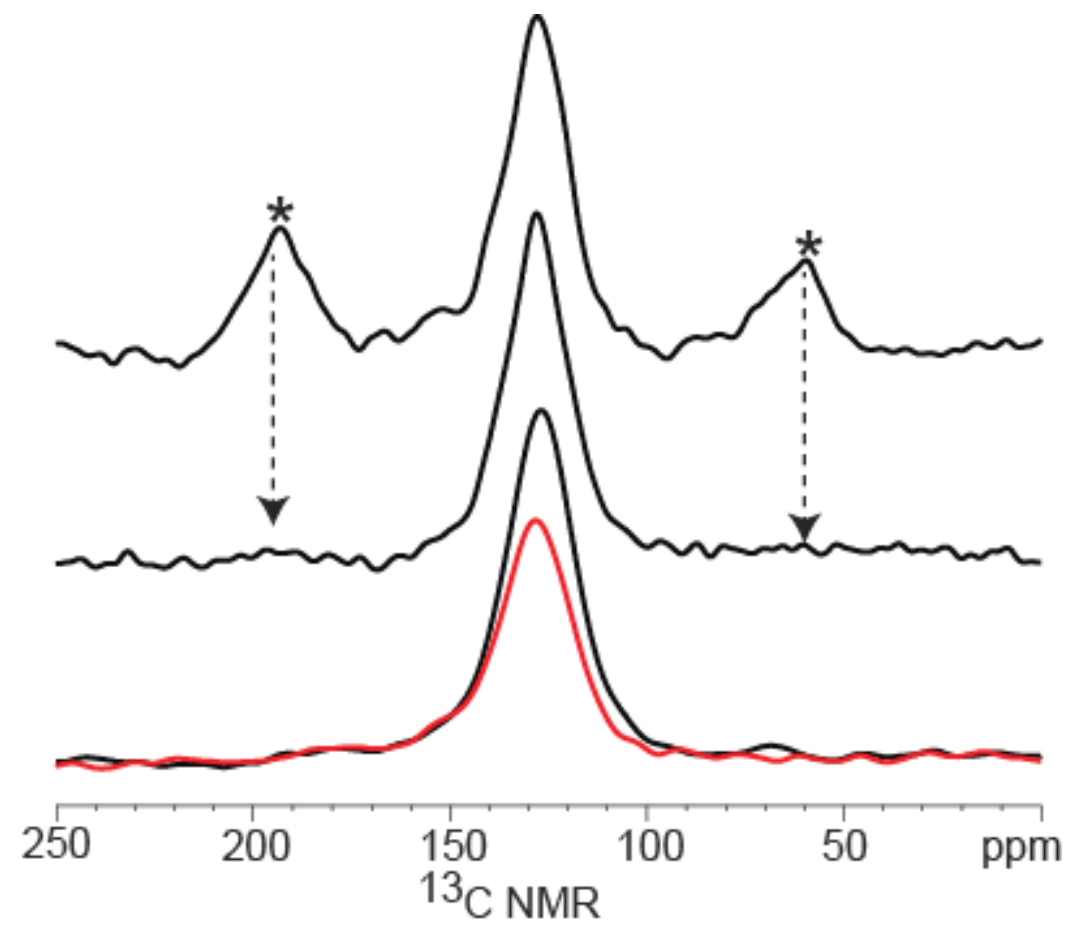

Figure S5. ${ }^{13} \mathrm{C}$ MAS NMR of biochar synthesized by co-pyrolysis of rice straw and calcium dihydrogen phosphate as per the description in Li, F., X. Cao, et al. (2014). "Effects of Mineral Additives on Biochar Formation: Carbon Retention, Stability, and Properties." Environmental Science \& Technology 48(19): 1121111218. (a) The ${ }^{13} \mathrm{C}$ CPMAS NMR of the biochar at $6 \mathrm{kHz}$ MAS, with "*” identifying the spinning sidebands. The CPMAS spectrum is not quantitative as is relies on the through-space transfer of polarization for ${ }^{1} \mathrm{H}$ to ${ }^{13} \mathrm{C}$ to generate the signal. As a result non-protonated carbons which are further away from the ${ }^{1} \mathrm{H}$ are underrepresented and are polarization transfer to carbons that are more than 3 bonds away from the protons is negligible. (b) The assignment of the spinning side bands 
is confirmed by acquiring the ${ }^{13} \mathrm{C}$ spectrum with the Total suppression of spinningsideband (TOSS) scheme as shown in (b), where only the spinning sideband signals are removed (as indicated by the dashed arrows). The true quantitative ${ }^{13} \mathrm{C}$ NMR signal of the biochar is acquired by a fully relaxed ( $10 \mathrm{~s}$ recycle delay), direct polarization-MAS, i.e. DPMAS NMR at faster MAS as shown in (c). The DPMAS spectrum is acquired at $12 \mathrm{kHz}$ MAS, which "spins away" the spinning side-bands and prevents overlap of the spinning side bands with any isotropic ("true") peaks in the 225-0 ppm range. The red spectrum is the DPMAS signal acquired after a 68 $\mu s$ of dipolar dephasing of only the protonated carbon species. The difference between the DPMAS spectrum without and with dipolar dephasing yields a quantitative value of $25 \%$ protonated-aromatic carbon species. As can be seen, by the DPMAS spectrum, there are negligible amounts of $\mathrm{C}=\mathrm{O}$, o-alkyl or ether carbon functionalities in the material. 
TECHNICAL DATA

\section{FEATURES}

MILES, QUEENSLAND

Sibelco's Trugel 100 is a civil engineering grade Bentonite mined and processed near Miles in Queensland. Trugel 100 contains a high proportion of the active mineral species montmorillonite, which has a unique structure and chemistry.

Trugel 100 is selectively mined and processed with strict adherence to the American Petroleum Institute (API) Spec Q1 in order to maintain consistent high quality characteristics. Sibelco Australia Limited is an authorized manufacturer of API standard drilling fluid materials.

Trugel 100 is processed to meet or exceed the requirements of API Spec 13A Section 11 OCMA grade Bentonite. Trugel 100 is tested and controlled to rigorous standards which ensure consistent chemical and physical properties resulting in predictable and repeatable performance. Sibelco Australia actively manages a Quality Management System certified to ISO9001:2008.

Sibelco's range of Trugel Bentonite is used in a wide range of civil and geotechnical applications. Trugel 100 typically finds use in drilling fluids, ground stabilization, dam sealing and waste containment. The following typical properties may help you to determine the suitability of the product to best suit your application.

Miles Trugel 100 (01/11)

\section{CHEMICAL \& ANALYTICAL DATA}

Mean Values. These Do Not Represent A Specification

Mean Percent by Weight

Silicon Dioxide

Aluminum Oxide

Titanium Dioxide

Iron Oxide

Calcium Oxide

Sodium Oxide

Magnesium Oxide

Potassium Oxide

Loss on Ignition

$\begin{array}{lr} & \text { (UAL 8.5) } \\ \left(\mathrm{SiO}_{2}\right) & \mathbf{6 3 . 8} \\ \left(\mathrm{Al}_{2} \mathrm{O}_{3}\right) & \mathbf{1 3 . 6} \\ \left(\mathrm{TiO}_{2}\right) & 0.3 \\ \left(\mathrm{Fe}_{2} \mathrm{O}_{3}\right) & 2.8 \\ (\mathrm{CaO}) & 0.2 \\ \left(\mathrm{Na}_{2} \mathrm{O}\right) & 2.3 \\ (\mathrm{MgO}) & 2.0 \\ \left(\mathrm{~K}_{2} \mathrm{O}\right) & 0.2 \\ \left(1000^{\circ} \mathrm{C}\right) & \mathbf{1 4 . 8}\end{array}$

Dry Screen (\% Passing 75 microns)

Wet Screen (\% Retained 75 microns)

Bulk Density

Cation Exchange Capacity

Moisture Content

Swelling Volume $\left(\mathrm{t} / \mathrm{m}^{3}\right)$
$(\mathrm{meg} / 100$

(\%)

$(\mathrm{ml} / 2 \mathrm{~g})$
78

2

1.0

80

10

32
PHYSICAL PROPERTIES

Mean Values. These Do Not Represent A Specification

Typical Suspension Properties

$\begin{array}{llll}\text { @ } \mathrm{Kg} / \mathrm{m}^{3} & 40 & 50 & 60\end{array}$

Apparent Viscosity

Plastic Viscosity

Yield Point

Gel - $10 \mathrm{sec}$

Gel - 10 min

Marsh Funnel

API Filtrate

$\mathrm{pH}$

$\begin{array}{lccc}(\mathrm{cP}) & 12 & 17 & 23 \\ (\mathrm{cP}) & 7 & 9 & 12 \\ \left(\mathrm{lb} / 100 \mathrm{ft}^{2}\right) & 5 & 8 & 11 \\ \left(\mathrm{lb} / 100 \mathrm{ft}^{2}\right) & 2 & 4 & 6 \\ \left(\mathrm{lb} / 100 \mathrm{ft}^{2}\right) & 4 & 8 & 12 \\ (\mathrm{sec} / \mathrm{l}) & 37 & 43 & 60 \\ (\mathrm{mls}) & 21 & 18 & 15 \\ & 9.5 & 9.5 & 9.5\end{array}$

\section{ORDERING INFORMATION}

Shipping Point:

Availability:

DISCLAIMER: Ranges and values of trial sample testing or on a Technical Information Sheet are typical or expected ranges and are not guaranteed ranges. You must satisfy yourself that the product is suitable for the purpose for which you intend to use it. Sibelco makes no representations as to suitability, fitness or merchantability.

HAZARD WARNING: Prolonged inhalation can cause delayed lung injury including silicosis, a progressive, disabling and sometimes fatal lung disease. In accordance with the National Occupational Health and Safety Commission's "Approved Criteria for Classifying Hazardous Substances", Free Crystalline Silica (Quartz) has been classified as a Hazardous Substance. This product contains Free Crystalline Silica (Quartz). The International Agency for Research on Cancer has determined that Free Crystalline Silica inhaled from occupational sources can cause cancer in humans. Risk of injury is dependent on the duration

Avoid creating dust when handling, using or storing the product. Use only with adequate ventilation to keep exposure low. Do not use as a dry abrasive blasting use appropriate to your workplace.

To prevent inhalation of airborne dust, wear respiratory protection in accordance with Australian Standard AS1715 and AS1716. To prevent potential irritation to eyes, wear eye protection in accordance with Australian Standard AS1337.

Please refer to the relevant Sibelco Australia Limited Material Safety Data Sheet (MSDS) for health hazard information before opening or using this product and take care when disposing of the empty bag/container (as it may contain product residue). If you do not have an MSDS, please ring the following ACOHS 24 hour emergency phone number: 1800638556 and you will be sent one.

FOR PRODUCT INFORMATION AND CUSTOMER SERVICE

AUST: $\begin{array}{lllll}\text { Adelaide }+61882408200 & \text { Brisbane } & +61739094500 & \text { Melbourne } & +61395865400 \\ & \text { Sydney }+61296377066 & \text { Perth }+61893621411 & \text { Newcastle } & +61240289300\end{array}$

NZ Sydney +61296377066
SIBELCO AUSTRALIA

ACN 000971844

BARYTES • BENTONITE • CLAY • DOLOMITE • FELDSPAR •ILMENITE • LIME • LIMESTONE • MAGNETITE • NEPH SYENITE • RUTILE • SILICA • TALC • ZIRCON 
Page 33 of 36 


\section{TECHNICAL DATA}

\section{FEATURES}

GILLMAN, SOUTH AUSTRALIA

Sibelco's Clay Q38 is produced from selectively mined clay deposits to ensure consistent chemical properties. The milling process ensures consistent sizing resulting in high quality, white clay.

Clay Q38 is tested and controlled to rigorous standards which ensure consistent chemical and physical properties resulting in predictable and repeatable performance. Sibelco Australia actively manages a Quality Management System certified to ISO9001:2008.

Sibelco's range of kaolin clays are used in a wide range of industrial applications. Clay Q38 typically finds use in applications such as adhesives, paints, grouts, rubber and chemical. The following properties may help you to determine the suitability of the product to best suit your application.

\begin{tabular}{l|lll}
\hline SPECIFICATION & & Gillman Q38 (01/11) \\
Sizing & $1.0 \%$ maximum +38 microns & Brightness R457nm & 72 minimum \\
Moisture & $2.0 \%$ maximum & & \\
Note: This product is manufactured to the requirements of the process specifications above. Typical properties are a consequence of the \\
process, nature of raw material and are measured at a lower frequency than the specified properties. These results are an average of historical \\
data.
\end{tabular}

CHEMICAL AND ANALYTICAL DATA

Mean Values. These Do Not Represent A Specification

Mean Percent by Weight

Silica

Alumina

Magnesia

Potash

Soda

Lime

Ferric Oxide

Titania

Loss on Ignition

Oil Absorption

$\mathrm{pH}$

Bulk Density (compacted)

Surface Area

Powder CIE Color
$\left(\mathrm{SiO}_{2}\right)$

$\left(\mathrm{Al}_{2} \mathrm{O}_{3}\right)$

$(\mathrm{MgO})$

$\left(\mathrm{K}_{2} \mathrm{O}\right)$

$\left(\mathrm{Na}_{2} \mathrm{O}\right)$

(CaO)

$\left(\mathrm{Fe}_{2} \mathrm{O}_{3}\right)$

$\left(\mathrm{TiO}_{2}\right)$

$\left(1000^{\circ} \mathrm{C}\right)$

(m/s/100g) (20\% Slurry)

$\left(\mathrm{g} / \mathrm{cm}^{3}\right)$

$\left(\mathrm{m}^{2} / \mathrm{g}\right)$

$\mathrm{L}^{*}$

$\mathrm{b}^{*}$
(UAL 8.5)

$\begin{array}{lr} & 48.7 \\ & 34.6 \\ & 0.4 \\ & 1.2 \\ & 0.2 \\ & 0.1 \\ & 0.9 \\ & 1.3 \\ \text { UAL 2.3 } & 12.1 \\ & \\ \text { UAL 2.9(a) } & 42 \\ \text { UAL 2.11 } & 7.2 \\ \text { UAL 2.10(a) } & 0.6 \\ \text { UAL 2.8(c) } & 21.1 \\ \text { UAL 2.1(e) } & 92.15 \\ & +0.58 \\ & +6.87\end{array}$

\section{PARTICLE SIZE ANALYSIS}

Mean Values. These Do Not Represent A Specification

$\%$ Finer

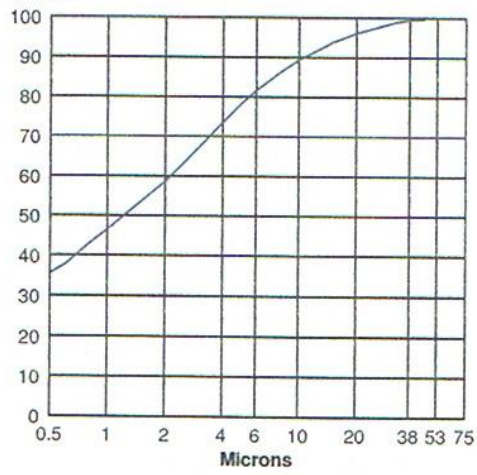

ORDERING INFORMATION

Shipping Point:

Gillman, South Australia

Availability:

DISCLAIMER: Ranges and values of trial sample testing or on a Technical Information Sheet are typical or expected ranges and are not guaranteed ranges. You must satisfy yourself that the product is suitable for the purpose for which you intend to use it. Sibelco makes no representations as to suitability, fitness or merchantability.

HAZARD WARNING: Prolonged inhalation can cause delayed lung injury including silicosis, a progressive, disabling and sometimes fatal lung disease. In accordance with the National Occupational Health and Safety Commission's "Approved Criteria for Classifying Hazardous Substances", Free Crystalline Silica (Quartz) has been classified as a Hazardous Substance. This product contains Free Crystalline Silica (Quartz). The International Agency for Research on and level of exposure. The risk Crystalline Silica inhaled from occupational sources can cause cancer in humans. Risk of injury is dependent on the duration Avo

Avold creating dust when handing, using or storing the product. Use only with adequate ventilation to keep exposure low. Do not use as a dry abrasive blasting To prevent

To prevent inhalation of airborne dust, wear respiratory protection in accordance with Australian Standard AS1715 and AS1716. To prevent potential irritation to (a)es, wear oyo prom

take care when disposing of the Australia Limited Material Safety Data Sheet (MSDS) for health hazard information before opening or using this product and hour emergency phone number: 1800638556 and you will be sent one.

FOR PRODUCT INFORMATION AND CUSTOMER SERVICE

AUST: Adelaide $+61882408200 \quad$ Brisbane $+61739094500 \quad$ Melbourne +61395865400

Sydney +61296377066 Perth +61893621411 Newcastle +61240289300

NZ Auckland +6499147010 Visit our website www sibelco,comiau

BARYTERS • BENTONITE • CLAY • DOLOMITE • FELDSPAR • ILMENITE • LIME • LIMESTONE • MAGNETITE • NEPH SYENITE • RUTILE • SILICA • TALC • ZIRCON 
Page 35 of 36 


\section{ECKALITE 2}

ECKALITE 2 is a high quality water washed china clay with controlled colour and particle size distribution.

\section{PHYSICAL PROPERTIES}

Brightness (ISO457nm)

$W \mathrm{t} \%+53$ Micron

Wt $\%$ +10 Micron

Wt $\%$-2 Micron

Moisture Content (Wt \%) (when packed)

$$
\text { - Powder }
$$

$\mathrm{pH}$

$$
\text { - Pellet }
$$

Typical Properties

Specific gravity

Surface Area $\left(\mathrm{BET} ; \mathrm{m}^{2} / \mathrm{g}\right)$

Oil Absorption $(\mathrm{g} / 100 \mathrm{~g})$

Mineralogical Analysis (\%)

Kaolinite

Mica

Quartz

CHEMICAL ANALYSIS

(by X-ray Fluorescence) (\%)

$\mathrm{SiO}_{2}$

$\mathrm{Al}_{2} \mathrm{O}_{3}$

$\mathrm{Fe}_{2} \mathrm{O}_{3}$

$\mathrm{TiO}_{2}$

$\mathrm{CaO}$

$\mathrm{MgO}$

$\mathrm{K}_{2} \mathrm{O}$

$\mathrm{Na}_{2} \mathrm{O}$

Loss on Ignition $\left(1000^{\circ} \mathrm{C}\right)$

\section{ECKALITE 2}

$80.0 \pm 1.0$

0.05 max

9.0 max

$73.0 \pm 3.0$

1.0 max

$10.0 \pm 2.0$

$5.0 \pm 0.5$

\section{6}

16

45

98

1

1

\section{7}

38

0.75

0.80

0.05

0.08

0.16

0.12

13.7

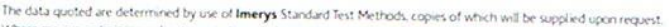

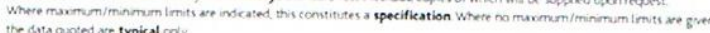

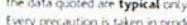

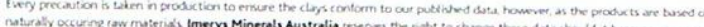
Wisten.

Imerys Minerals Australia Pty Ltd

Clenelg Highway Pittong Linton Victoria 3360 Australia

Telephone (03) 53447205 Facsimile (03) 53447308

eMail cosulliv@imerys.com

Imerys pats se S-EL2 March 2002

(B)

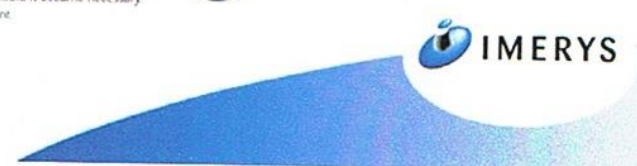

